\title{
СОВРЕМЕННЫЙ ВЗГЛЯД НА ТЕРМОБИОЛОГИЮ С ПОЗИЦИИ ИЗУЧЕНИЯ РЕПТИЛИЙ В.А.Черлин
}

Петрозаводский государственный университет, Петрозаводск, Россия

E-mail: cherlin51@mail.ru

Статья поступила в редакцию 25.01.2016; принята к печати 03.03.2016

Описаны термобиологические особенности рептилий, влияющие на все стороны их жизнедеятельности. Приведены методологические новации: активность рептилий необхдимо разделять на статусы (полную и неполную активности, неактивное состояние) и соответствующие им формы, а все данные должны собираться и обрабатываться отдельно по этим формам активности. Введен ряд новых понятий и описаны закономерности, не выявляющиеся в других вариантах исследований: стабилизация высокой температуры тела в эволюции позвоночных; наличие унифицированной системы термобиологических показателей, разделенных на термоэкологические и термофизиологические; наличие комплекса видоспецифичных, стабильных, неизменных популяционно, географически и сезонно термофизиологических характеристик гомеостаза. Основным механизмом индивидуальных термальных адаптаций рептилий является не пластичность термофизиологии, а стремление сохранить в неизменности термофизиологические показатели гомеостаза в любых условиях среды за счет поведенческой подстройки пространственно-временных структур суточной и сезонной активности. Описан комплекс элементарных терморегуляционных реакций в центральной нервной системе рептилий и составленные из них модели терморегуляции. По особенностям терморегуляции рептилии делятся на термонейтрально и термостабильно активных. Показано, что эволюционные изменения в видоспецифичных термофизиологических характеристиках рептилий вряд ли могут быть проявлениями адаптогенеза. Преимущественная направленность реализации принципа стабилизации высокой температуры тела в эволюции позвоночных у рептилий как высших эктотермов - энергетическая экономичность и эффективность, а у эндотермов - экологическая конкурентоспособность, являющаяся интегральным показателем общей приспособленности. Приведены общие положения парадигмы термобиологии рептилий.

Ключевые слова: термобиология, рептилии, термальный гомеостаз, адаптации.

\section{A MODERN OUTLOOK ON THERMAL BIOLOGY FROM THE VIEWPOINT OF STUDYING THE REPTILES \\ V.A. Cherlin \\ Petrozavodsk state university, Petrozavodsk, Russia \\ E-mail: cherlin51@mail.ru}

The thermal biology features of reptiles, which are closely related to all aspects of their vital activity, are reviewed, and methodological innovations for studying them are introduced. It is suggested to categorize reptile activity according to statuses defined as inactivity and complete and incomplete activity and featuring corresponding activity patterns. Data on each of such patterns must be collected and processed separately. It is due to these methodological innovations that several new concepts could be introduced and a number of regularities unnoticeable upon using other approaches could be described, i.e., the stabilization of high body temperature in vertebrates evolution; the existence of a unified complex of thermobiological parameters, which may be categorized as thermoecological and thermophysiological; and the existence of an essential species-specific complex of stable, geographically and seasonally invariable physiological characteristics of thermal homeostasis. The primary mechanism of individual thermal adaptations in reptiles is not the plasticity of thermal physiology, but the tendency to keep the main thermophysiological indicators of homeostasis immutable under any of environmental conditions due to the behavioral tuning of the spatial-temporal patterns of daily and seasonal activity. A set of elementary thermoregulatory responces mediated by the central nervous system of reptiles is described, and several thermoregulation models for different reptile groups are constructed out of such responces. Based on differences in thermoregulation, reptiles are divided into thermoneutral and thermostable activity groups. It is shown that evolutionary changes in species-specific thermophysiological characteristics are unlikely to be the manifestations of adaptogenesis. The primary trends of the implementation of the principle of stabilization of high body temperature in the evolution of vertebrates are energy saving and efficiency in reptiles, which are higher ectotherms, and competitiveness as an integrated indicator of the overall adaptive fitness in endotherms. The general provisions of the paradigm of thermal biology of reptiles are suggested.

Keywords: thermal biology, reptiles, thermal homeostasis, adaptations

\section{ВВЕДЕНИЕ}

За вторую половину ХХ в. в науке сложились определенные представления о биологии пресмыкающихся, о том, как организована их жизнедеятельность в естественных условиях, чем и как она регулируется. Нельзя сказать, чтобы эти представления были очень сложными.

В советской науке они опирались, прежде всего, на классические эколого-физиологические исследования А.Д. Слонима и его школы [26-31 и др.], хотя в целом рептилий они касались мало. Было установлено, что множество физиологических функций у пресмыкающихся (метаболизм, сердечная деятельность, сократимость мышечных тканей и т. п.) прямо связаны с температурой. Температура их тела достаточно сильно и примитивно зависит от температур среды. При активности они могут поддерживать ее на уровне примерно $30{ }^{\circ} \mathrm{C}$ или выше, делают они это благодаря тепловым факторам внешней среды и простейшим поведенческим реакциям. Термогенеза для 
поддержания высокой температуры тела практически нет. Следовательно, и терморегуляции - никакой... Их общебиологическая структура и система связи со средой обитания организована сложнее, чем у амфибий, но намного примитивнее, чем у млекопитающих и птиц. В эволюционном плане рептилии более примитивная форма организации, чем птицы и особенно млекопитающие. Адаптивно направляемая пластичность эколого-физиологических характеристик позволяет рептилиям приспосабливаться к различным условиям среды, являясь ресурсом для отбора и базой их адаптабельности к внешней среде.

Зарубежные исследователи значительно серьезнее занимались этой группой животных. Особенно активно развивалось это направление исследований с 60-х гг. прошлого века. Было выяснено, что наиболее аккуратно температура тела поддерживается рептилиями при определенных физиологических процесcax - переваривании пищи, в некоторых стадиях гаметогенеза, при беременности $[63,72,78,87,93,100$, $108,110,134]$, что она чрезвычайно важна в повседневной жизни, поскольку сильно влияет на результативность охоты [92], двигательной активности, избегания хищников [62] и многих других необходимых поведенческих реакций.

Большой вклад отечественных ученых в экологическую физиологию животных в целом (но прежде всего - теплокровных) неоспорим. Описанные ими эколого-физиологические закономерности объективно существуют. Но однозначная трактовка экологофизиологических реакций и характеристик пресмыкающихся как базы их адаптаций к условиям среды вызывала нашу настороженность, как позже выяснилось - небезосновательную [50, 80].

Первой статьей, в которой было обращено серьезное внимание на некоторые важнейшие закономерности в регуляции температуры тела у рептилий, была работа С.С. Либерман и Н.А. Покровской по биологии прыткой ящерицы (Lacerta agilis) [19], опубликованная еще в 1943 г., за год до выхода знаменитой статьи Р.Б. Коула и К.М. Богерта [83], которая сейчас во всем мире признана «отправной точкой» термобиологии рептилий. Именно в работе С.С. Либерман и Н.А. Покровской впервые был отмечен целый ряд важнейших аспектов [49], которые другими исследователями не были замечены. С тех пор число научных публикаций, посвященных физиологической экологии рептилий, исчисляется уже многими тысячами. Но до сего времени не существует общепринятой единой концепции физиологической экологии рептилий.

Материалы наших собственных исследований и наблюдений над пресмыкающимися в лаборатории и, особенно, в полевых условиях привели к необходимости скорректировать прежде всего методы сбора и обработки материала. Методологические новшества дали и новые знания. Их осмысление привело к пониманию термобиологии рептилий, их физиологической экологии как научного направления, логично связывающего воедино практически все стороны их биологии - от морфологии, биохимии и физиологии до экологии и филогении. Это дало возможность намного более четко понять значение термобиологии в общей системе биологических знаний о рептилиях, а также место самих рептилий в системе животного мира и ее эволюции, оценить значимость различий между двумя эволюционными направлениями развития позвоночных - эктотермными и эндотермными животными.

Основная задача данной статьи - представить доказательно, но в как можно более краткой форме эту единую концепцию.

\section{МЕТОДОЛОГИЧЕСКИЕ НОВШЕСТВА}

\section{1. Традиционная методика сбора и обработки первичных данных}

Начало наших исследований мало отличалось от того, что делали (и делают до сих пор) остальные полевые герпетологи, изучающие температурные условия обитания рептилий. На рис. 1 представлены варианты исследований по термобиологии некоего гипотетического, дневного вида достаточно теплолюбивых рептилий (скажем, ящерицы) где-то в зоне южных степей.

Стандартная (обычная, наиболее часто применяемая большинством исследователей и изначально применявшаяся нами тоже) обработка стандартно полученных материалов дает следующие результаты (рис. $1 A, Б$ ). В целом весной, когда в среде еще прохладно, температура тела при встречах некоего вида рептилий оказывается ниже (рис. $1 A$ ), чем при высоких температурах среды жарким летом (рис. 1Б). Этот результат логичен, ожидаем и понятен. Средняя арифметическая из совокупности температур тела при встречах рептилий в зоне активности (которая часто называется предпочитаемой температурой) весной составляет примерно $24{ }^{\circ} \mathrm{C}$, а летом - примерно $32,5^{\circ} \mathrm{C}$. Диапазон температур тела при встречах (который часто называется «диапазоном добровольных температур») составляет весной $13-36^{\circ} \mathrm{C}$, а летом $-22-38^{\circ} \mathrm{C}$.

Получается, что весной термобиологические показатели активности рептилий данного вида (добровольные температуры - $13-36{ }^{\circ} \mathrm{C}$ и предпочитаемые температуры $-24^{\circ} \mathrm{C}$ ) существенно ниже, чем летом (добровольные температуры - 22-38 ${ }^{\circ} \mathrm{C}$ и предпочитаемые температуры $-32,5^{\circ} \mathrm{C}$ ). Таким образом, делается вполне обоснованный конкретным материалом вывод о пластичности термобиологических показателей, которая позволяет рептилиям адаптироваться к меняющимся и порой жестким условиям среды.

Но наши наблюдения над биологией рептилий и изучение их физиологической экологии показали, что дело обстоит совсем не так просто и однозначно, что в методику исследований необходимо внести серьезные коррективы.

\section{2. Методологические новации}

Наши исследования показали, что в целом активность рептилий делится на ряд общих состояний. Первое упоминание в литературе о значении неоднородности феномена активного состояния в термобиологии рептилий мы обнаружили в работе С.С. Либерман и Н.В. Покровской [19]. Они использовали понятия «полная активность», «неполная активность» и «неактивное состояние» у прытких ящериц L a certa agilis. Под неполной активностью они понимали состояние, когда ящерицы греются и еще не заняты в полной мере своими обычными делами, характерными для них при полном нагреве 

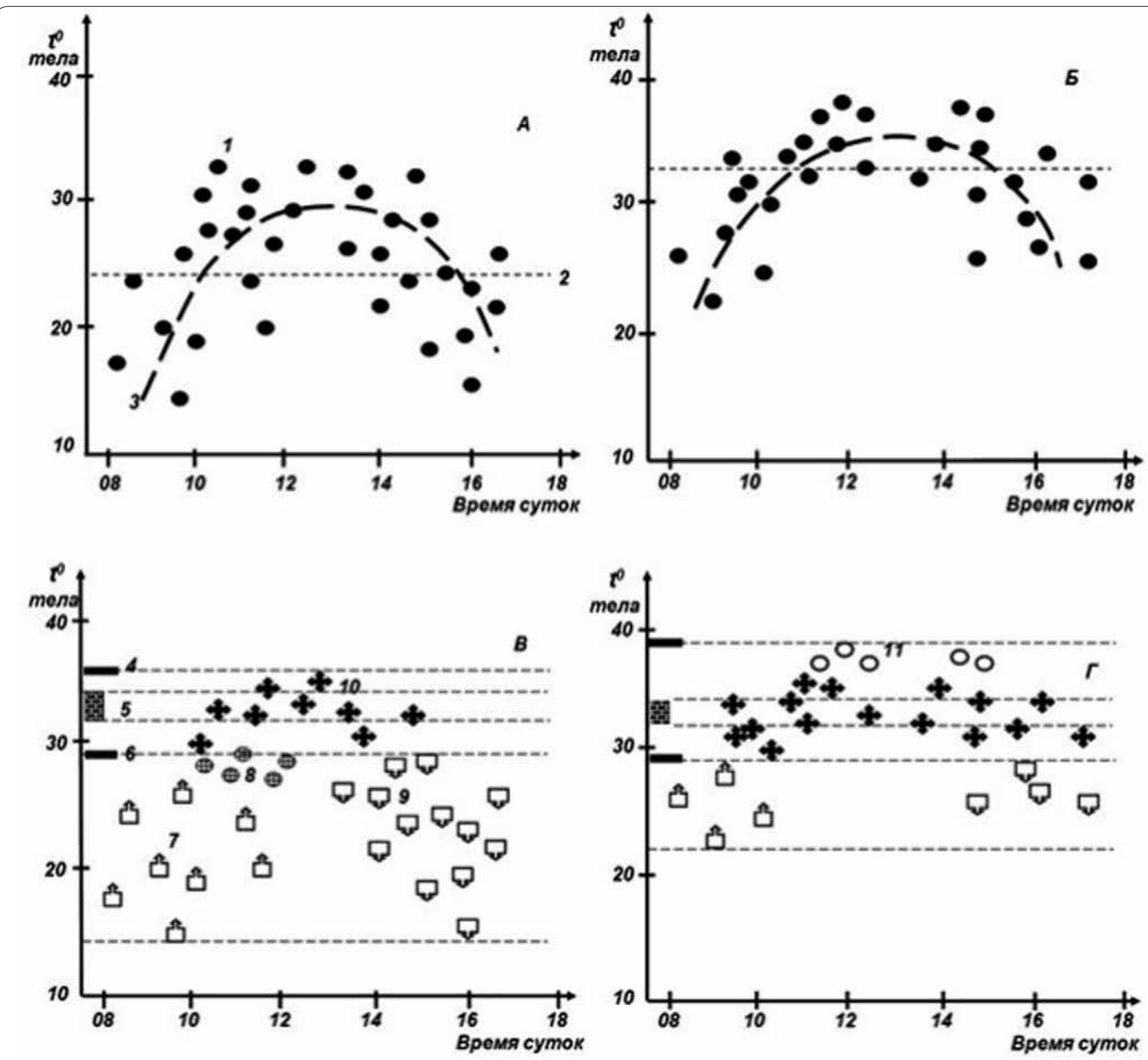

Рис. 1. Варианты исследований по термобиологии гипотетического вида рептилий в разные сезоны. $А$ и $Б$ - исследования без учета форм активности; В и Г - исследования с учетом форм активности; А и В - весна; Б и Г - лето. 1 - температуры при встречах ящериц; 2 - среднее арифметическое температур тела рептилий при встречах; 3 - усредненный ход температуры тела в светлое время суток; 4 - максимальная температура полной активности; 5 - модальный диапазон термостабилизации; 6 - минимальная температура полной активности; 7 - нагревание; 8 - псевдо-термостабилизирующее поведение (ТСП, см. определение в разделе 1.2 ниже); 9 - остывание; 10 - ТСП; 11 - добровольный перегрев [по 48]

тела. При полной активности, наоборот, ящерицы уже были полностью нагреты и занимались в полном объеме своими обычными рутинными делами. И хотя авторы четко не определили понятия «полная активность», «неполная активность» и «неактивное состояние», они подробно описали проявления этих состояний. Таким образом, несмотря на недоработки само по себе разделение активности на статусы этими авторами уже было очень важным.

Через год появилось второе упоминание о статусах активности в хорошо известной в мире статье Р. Коула и К. Богерта [83]. Упомянутый ими «диапазон нормальной активности» (normal activity range) - диапазон температур, при котором животные полностью нагреты и активны, то есть ведут обычную рутинную деятельность [83, с. 277]. По смыслу этот диапа- зон полностью соответствует диапазону температур полной активности по С.С. Либерман и Н.В. Покровской [19].

Больше мы не встречали в литературе специальных упоминаний на эту тему.

Кроме того, мы выяснили [51, 54 и др.], что полная активность состоит у рептилий из ряда стандартных форм, в которых рептилии осуществляют взаимосвязь статусов активности рептилий с температурным фактором. В каждой из этих форм активности рептилии поддерживают какую-то одну из стратегий отношения к температуре (либо удерживают ее на каком-то определенном уровне, либо направленно ее повышают или понижают, либо противодействуют избыточному нагреванию или слишком быстрому остыванию, либо имеют возможность вообще не 
обращать на нее внимания), а также имеют возможность реализовать и реализуют вполне конкретный набор поведенческих актов, важных для жизнедеятельности индивидуального животного, популяции и вида в целом (активные локомоции, питание, эффективная защита, проявление полового поведения, социальные взаимодействия и т. п.). Выделение форм активности позволяет более полно и эффективно исследовать температурные предпочтения и границы, физиологические закономерности, связанные с температурой, изучать их экологию и многое другое $[48,80]$.

Не будем здесь повторять определения всех терминов и понятий, приведенных нами в предыдущих работах $[48,80]$. Только перечислим принятые нами статусы и формы активности, а также термобиологические показатели.

Формы активности рептилий в неактивном состоянии: ночной покой, анабиотические состояния.

Формы активности рептилий в состоянии полной активности: термостабилизирующее поведение (ТСП), термонейтральное поведение (ТНП), терминг, добровольный перегрев, дневной отдых.

Формы активности рептилий в состоянии неполной активности: нагревание, остывание, псевдоТСП.

Именно выделение состояния полной активности и ее форм позволяет корректно выделять и определять конкретные величины ряда важнейших термофизиологических показателей активности у рептилий - диапазона температур полной активности и диапазона термостабилизации (рис. 1), четко распознавать и определять термобиологические характеристики различных видов рептилий, стандартизировать их смысловое наполнение, методику их определения [42, 43]. И только благодаря этому полученные таким обра-

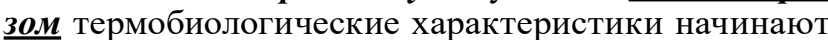
проявлять четкие закономерности (о них - немного ниже). И тогда становится понятно, почему эти важнейшие закономерности не увидели другие исследователи, применявшие в своей работе стандартные, общепринятые методики $[42,47]$.

Кроме того, стало понятно, что комплекс термобиологических характеристик у рептилий неоднороден. Эти показатели необходимо разделить на две группы, в смысловом отношении сильно друг от друга отличающиеся. Это термофизиологические и термоэкологические показатели [48, 53, 80]. О необходимости такого разделения до нас уже упоминали авторитетные авторы $[83,100]$, но они не довели работу до реализации своих собственных идей в этом направлении, а последователи этих ученых вообще не обратили внимания на их важные мысли.

Функционально термофизиологические показатели характеризуют физиологическую норму реакции данного вида на температуру, температурные предпочтения, описывают полные, потенциально возможные границы активности и выносливости рептилий. К ним относятся: показатели полной активности - диапазон температур полной активности, минимальная и максимальная температуры полной активности; показатели температурных предпочтений - диапазон термостабилизации, модальный диапазон термостабилизации, оптимальные температуры; показатели температурной выносливости рептилий - критические минимум и максимум тем- пературы тела (температуры тела при наступлении холодового и теплового шоков). Здесь надо пояснить, что диапазон термостабилизации по биологическому смыслу - это не оптимальные (они далеко не для всех процессов оптимальны) и не предпочитаемые (их далеко не всегда животные предпочитают) температуры тела. Это именно «диапазон термостабилизации», поскольку, когда животные реально заняты стабилизацией температуры тела, то стабилизируют они ее именно в этом диапазоне. Кроме того, в комплекс термофизиологических показателей входят: температуры ночного покоя, диапазон суточных колебаний температуры тела, «запас температурной прочности вида» (диапазон температур тела между максимальной температурой полной активности и критическим максимумом).

Термоэкологические показатели функционально характеризуют температурные параметры активности рептилий данного вида в конкретных экологических условиях, которые тем или иным способом ограничивают проявления термобиологических показателей. Термоэкологические показатели являются поэтому неполными. Это - аналоги соответствующих термофизиологических характеристик, только проявляющиеся в конкретных климатических и экологических условиях.

\section{3. Новые данные, полученные благодаря применению новых методических приемов}

Теперь, после «теоретической подготовки», можно вернуться к материалам обработки нашего абстрактного примера с изучением термобиологии рептилий (рис. 1). Все описанные выше теоретические положения проявились при соответствующем варианте обработки материалов исследований (рис. $1 B, \Gamma$ ). Так, у некоего вида рептилий весной, когда температуры среды еще низкие, температуры тела при полной активности оказываются в диапазоне $28-36{ }^{\circ} \mathrm{C}$ (рис. $1 B)$, а температуры термостабилизации - 33-34 ${ }^{\circ} \mathrm{C}$ (что на $10^{\circ}$ выше диапазона «оптимальных» или предпочитаемых температур в первом варианте). Жарким летом эти температуры у них составляют соответственно $28-38$ и $33-34{ }^{\circ} \mathrm{C}$ (рис. $1 \Gamma$ ). Причем верхняя граница температур полной активности летом на $2{ }^{\circ} \mathrm{C}$ выше, чем ранней весной, но происходит это вследствие того, что летом, ближе к середине дня, температуры среды поднимаются слишком высоко и быстро, а ранней весной просто не хватает внешних температур, чтобы нагреть тело до $38^{\circ} \mathrm{C}$. Другими словами, это небольшое сезонное различие в показателях связано не с физиологическими, а с чисто экологическими причинами.

Этот результат демонстрирует, что основные термофизиологические показатели активности рептилий одного вида в разные сезоны даже при сильно различающихся климатических условиях вовсе не пластичны, как ожидается на основании теоретических воззрений классической экологической физиологии, а практически одинаковы. Это продемонстрировано и на конкретных, реальных примерах для ряда видов рептилий $[43,48,53]$. Следовательно, данный, скорректированный вариант сбора и обработки материалов, учитывающий формы активности рептилий (рис. $1 B, \Gamma$ ), приводит к выводам, диаметрально противоположным первому, не учитывающему форм активности (рис. $1 A, \overline{ })$. 
Выходит, что получить просто цифровую выборку по температурам встреч рептилий в природе - недостаточно. Обработка такого материала грозит серьезными ошибками. Только сочетание корректно сформированной выборки по температурам тела с обязательным учетом форм активности данного вида рептилий позволяет получить объективную картину происходящего и сделать корректные выводы [43, 47, 48].

\section{2. НОВЫЙ ВЗГЛЯД НА НЕКОТОРЫЕ АСПЕКТЫ ТЕРМОБИОЛОГИИ РЕПТИЛИИ}

\section{1. Что рептилии на самом деле регулируют, контролируя температуру тела?}

Некоторое сомнение вызывает у ряда ученых вопрос: поскольку у рептилий температура тела очень сильно зависит от температур среды и мало от нее отличается, правомочно ли говорить, что они способны регулировать температуру своего тела?

Ответ на этот вопрос поясним на двух примерах.

Песчаная круглоголовка Phrynocephalus interscapularis (термостабильно активный вид рептилий) выходит утром из норы, в которой температура весной составляет $24-30{ }^{\circ} \mathrm{C}$ в разное время суток. Поверхность песка освещается солнцем, и она в течение дня нагревается от $18-20{ }^{\circ} \mathrm{C}$ утром и до $50-60{ }^{\circ} \mathrm{C}$ в середине дня. Температура приземного слоя воздуха в середине дня составляет $32-35^{\circ} \mathrm{C}$. В этих условиях температура тела ящериц, находящихся в состоянии полной активности, удерживается в диапазоне 37,5-45,0 ${ }^{\circ} \mathrm{C}$ [51]. Это значит, что ящерицы благодаря использованию разнообразных поведенческих приемов направленно поддерживают температуру тела в достаточно узком диапазоне, отличном от температур окружающей среды. В этом и проявляется у песчаных круглоголовок регуляция температуры тела.

Сцинковый геккон Teratoscincus scincus (термонейтрально активный вид рептилий) бо́льшую часть времени в сутках проводит в норах, где температура держится весной $18-30{ }^{\circ} \mathrm{C}$ в разных местах. К концу лета - началу осени она поднимается там до 28-32 ${ }^{\circ} \mathrm{C}$. На поверхность гекконы выходят исключительно в ночное время и встречаются там при температурах среды и тела примерно от 16 до $32{ }^{\circ} \mathrm{C}$. В это время температуры тела ящериц чаще всего совершенно не отличаются от температур воздуха и почвы, да и в норах они соответствуют температуре норы. Но это не значит, что тогда у них отсутствует регуляция температуры тела, потому что ящерицы не просто поддерживают у себя температуру тела в определенном интервале, но и организуют необходимую для себя ее суточную динамику. Они очень точно выбирают место и время своего нахождения, что позволяет им бо́льшую часть суток иметь температуру тела 28-32 ${ }^{\circ} \mathrm{C}$ [55]. После выхода на поверхность они стремятся к тому, чтобы температура тела либо помедленнее опускалась, либо не падала ниже $16^{\circ} \mathrm{C}$, для чего часто уходят в норы греться (в норах в это время температура не ниже $30^{\circ} \mathrm{C}$ ). Таким образом, в каждой конкретной точке пространства гекконы чаще всего имеют температуру тела, соответствующую температурам среды. Но нет такой точки в пространстве, используемом ими для жизни, где суточная динамика температур среды все время была бы такой, которая соответствовала бы необходимой для физиологии ящериц суточной динамике температуры их тела. Гекконы же, используя разнородное «термальное поле» среды, организуют необходимую для себя суточную динамику температуры тела, которая существенно отличается от динамики температур среды в любой из точек пространства. Следовательно, можно определенно сказать, что и они вполне активно и успешно регулируют суточную динамику температуры своего тела, хотя, действительно, она очень сильно зависит от температур среды.

Теплокровные животные поддерживают у себя один, узкий диапазон высокой температуры глубоких частей тела. Рептилии же организуют у себя не столько поддержание конкретного уровня температуры тела, сколько ее суточную и сезонную динамику в режиме, отличном от динамики температур среды, за счет терморегуляционных поведенческих и некоторых (ограниченных) физиологических реакций и используя также сильную «оперативную» зависимость температуры тела от внешних тепловых факторов [48]. Стабилизация температуры тела на определенном, видоспецифичном, высоком уровне происходит у них далеко не всегда [48].

\section{2. Каков биологический смыл регуляции температуры тела у рептилий?}

\section{Реализация принциипа стабилизацчии высокой температуры тела в эволючии позвоночных животных}

Принцип стабилизации высокой температуры тела в эволюции позвоночных животных: у позвоночных животных в процессе эволючуии наблюдается направленность на все бо́льшую стабилизацию высокой температуры тела $[25,41,45]$. Биологический смысл этого принципа заключается в том, что температура тела, то есть температура, при которой реально функционируют биохимические соединения и, особенно, ферменты, без которых невозможны процессы жизнедеятельности, должна быть достаточно высокой, чтобы работа ферментов была энергетически оптимальной (рис. 2), но и не настолько высокой, чтобы нарушать белковые и другие важнейшие для жизни соединения $[25,41]$. А.В. Рюмин предполагал, что такое равновесие устанавливается при температуре около $37^{\circ} \mathrm{C}$. Кроме того, повышение температуры тела способствует интенсификации многих важнейших физиологических процессов (переваривание пищи, освобождение энергии для физической активности и т. п.), которые должны усиливать энергообеспеченность любой активности и, особо, термогенеза у эндотермов. А.В. Рюмин [24, 25] также считал, что одно из важнейших направлений развития позвоночных животных, связанное с усилением эффективности деятельности животных в среде - усложнение морфологического развития и функционирования центральной нервной системы, а это, в свою очередь, реально только при достаточно высокой скорости проведения нервных импульсов и других процессов, которые как раз и ускоряются при высоких температурах. Следовательно, по его мнению, одним из важнейших условий прогрессивного эволюционного развития у позвоночных является повышение температуры их тела. 


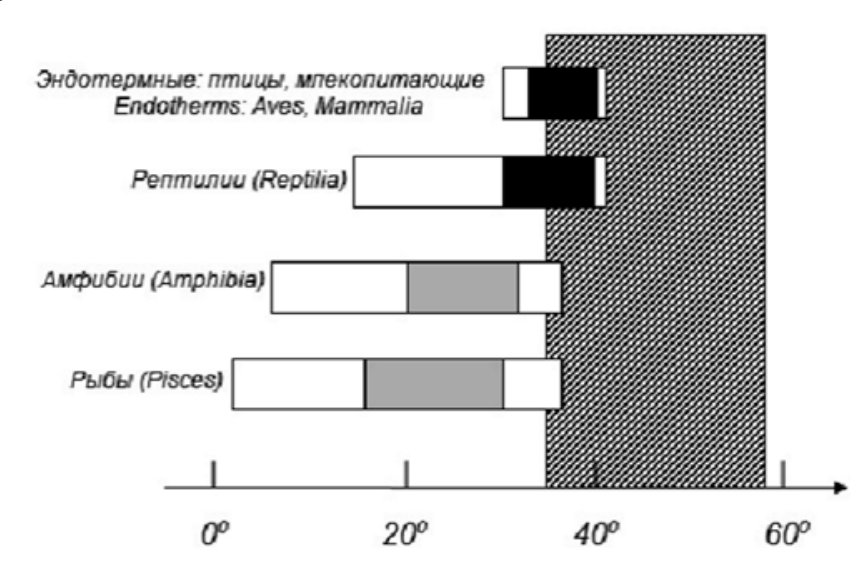

Рис. 2. Стабилизация высокой температуры тела в эволюции позвоночных животных. Заштрихованная зона - область оптимальной работы большинства ферментов. Белые прямоугольники - зона активности животных. Серые и черные прямоугольники внутри белых - зона оптимальных, добровольно избираемых температур для животных; серые не очень четкая регуляция температуры; черные - точная регуляция (по [41, 45])

Рептилии - эктотермные животные. Эндогенных, биохимических механизмов термогенеза, специально направленных на повышение температуры тела, у них нет. У рептилий (особенно у некрупных видов, которых среди пресмыкающихся подавляющее большинство) повышение температуры тела и ее периодическая стабилизация на высоком уровне осуществляется в основном за счет теплоты, получаемой извне, от различных тепловых факторов внешней среды.

Таким образом, удержание высокой температуры тела для рептилий (хотя бы в течение части суток) является важной необходимостью, определяемой частично общебиологическими причинами, частично индивидуальными физиологическими потребностями (подвижность, переваривание пищи, гаметогенез, беременность и т. п.).

Реализацุия принщฺипа автономизацуии жизнедеятельности живой системь

Принцип автономизации жизнедеятельности живых систем: «Эволюционное развитие живых систем направлено на уменьшение зависимости их жизнедеятельности от внешних для них факторов» [45, с. 31].

Реализация этого принципа выражается в своеобразной диалектике связи температуры тела рептилий со средой - благодаря активному использованию и развитию специфических комплексов физиологических и поведенческих регуляторных реакций, рептилии стремятся усилить оперативную связь температуры тела с микроклиматическими термальными факторами среды (температурами воздуха, субстрата, инсоляцией, тепловым излучением окружающих предметов), но за счет этого одновременно ослабить зависимость своей жсизнедеятельности от климатических условий географических регионов обитания, сохраняя за счет изменения пространственно-временной структуры суточной активности неизменный комплекс стабильных физиолого-экологических характеристик гомеостаза и организуя необходимую для себя суточную и сезонную динамики температуры тела в любых условиях среды [45].

\section{3. За счет чего и как регулируется у рептилий температура тела?}

\subsection{1. Морфологические особенности, влияющие на теплообмен и температуру тела}

У рептилий существует ряд морфологических характеристик, влияющих на теплообмен тела со средой. Часть из них являются постоянными, неизменными, видоспецифическими особенностями.

Прежде всего, следует обратить внимание на размеры тела. Любой маленький предмет имеет бо́льшую относительную поверхность, чем большой той же формы. Это значит, что меньший предмет быстрее нагревается и остывает. Это обстоятельство имеет особое значение для пресмыкающихся. Если они обитают в холодных условиях (в горах, в высоких широтах) или, наоборот, в жарких (степи, пустыни), преимущество получают мелкие виды, способные очень оперативно изменять температуру тела, то есть быстро нагреваться и остывать, избегая опасных для жизни высоких или низких температур. В теплом, мягком, ровном и влажном климате размеры тела пресмыкающихся не играют такой серьезной роли, и там появляется возможность одинаково успешно обитать и мелким, и крупным пресмыкающимся.

Изменения в щитковании рептилий коррелятивно связаны с глубокими физиологическими адаптациями к условиям мест обитания [98]. Исследования особенностей щиткования у одних и тех же видов рептилий, обитающих в разных климатических условиях, показали, что чем более жарким и сухим оказывается климат биотопов, тем количество чешуй на теле рептилий оказывается больше [35-37, 54, 75, 82 , $85,89,98,105,118,119,128]$, что может объясняться разными причинами [3-6 и др.].

Окраска и строение покровов рептилий способствуют тому, что во влажных местах обитания средняя отражающая способность покровов значительно ниже, чем у аридных видов [56, 66, 76, 77, 81, 88, 116 , $121,124,129,131,132$ и др.], что позволяет последним уменьшать тепловую нагрузку.

У любого предмета, и у тела пресмыкающегося в том числе, имеется определенная степень температурной инерции, то есть оно нагревается и остывает не сразу. Это связано с массой тела, его относительной поверхностью, со скоростью движения воздуха [86], с тем, что у мелких животных термальное сопротивление пограничного слоя больше, чем изолирующего [70]. У мелких рептилий возможности контролировать теплопроводность тела ничтожны [90]. У рептилий с крупным телом вследствие большой массы и существенных теплоизоляционных свойств покровов температура тела в течение суток изменяется лишь незначительно, несмотря на большие изменения температуры среды [70 и др.].

У разных рептилий отмечено наличие различий в температуре головы и туловища [94, 104, 135, 136 и др.]. Отчасти это связано с чисто физическими причинами: голова, отграниченная от туловища, имеет бо́льшую относительную поверхность, чем тело, и поэтому сильнее подвержено влиянию тепловых факторов среды [122]. 
Существуют и другие, частные морфологические особенности. Так, у песчаной игуаны Uma notata носовые ходы имеют форму петли или буквы U и функционируют как теплообменники: горячий вдыхаемый воздух охлаждается примерно до температуры тела и увлажняется, а при выдохе он забирает избыточное тепло из организма [112].

Некоторые морфологические особенности выступают у рептилий как физиологические реакции на изменение температуры. Так, у степных агам Trapelus sanguinolentus при повышении температуры тела цвет его становится светлее, вплоть до почти белого, отражательная способность кожи при этом увеличивается, что препятствует нагреванию. Когда же температура тела низкая, окраска тела намного более темная, ее отражательная способность уменьшается, и это помогает животному быстрее нагреться.

Эти и множество других особенностей морфологии рептилий влияют на их терморегуляционные возможности.

\subsection{2. Основные принципы регуляции температуры} тела центральной нервной системой рептилий

Физиолого-этологическая схема терморегуляции организована по принципу отрицательной обратной связи $[11,18,21,100,111]$. В рамках этой схемы комплекс видоспецифичных, неизменных термофизиологических характеристик гомеостаза представляет терморегулирующие характеристики, а комплекс термоэкологических показателей - терморегулируемые характеристики.

Регуляция температуры тела у животных осуществляется двумя основными способами - физиологическим и поведенческим. У рептилий наиболее полно развита поведенческая терморегуляция, которая оперирует в основном теплотой, поступающей извне $[46,48,115]$, хотя, безусловно, определенное значение имеет и тепло от работы мышц, что особенно важно для крупных животных. Также у них имеется и большой набор физиологических реакций, направленных на перераспределение тепла в теле, позволяющих быстрее нагревать все тело или охлаждать его [обзор в 46, 47].

Общим между физиологической и поведенческой терморегуляциями является то, что в обоих случаях регуляция температуры тела возможна лишь при развитии механизмов контроля над температурой тела, формирующихся в центральной нервной системе.

Собственные исследования и анализ научных публикаций [102 и мн. др.] показали, что основные варианты построения общих схем терморегуляции у рептилий, а также и у других эктотермных позвоночных животных, организуются из определенного, вполне конечного набора элементарных терморегуляционных реакций - ЭТР [45, 46]. По нашему мнению, из них в процессе эволюции, как из кирпичиков, складываются три общих схемы терморегуляции разных групп рептилий (рис. 3).

1) Схема регуляции температуры тела в период полной активности.

ЭТР 1. Реакция поддержания четкой верхней границы температуры тела (рис. 3-1). Это регулятор верхней границы температуры тела в состоянии полной активности.
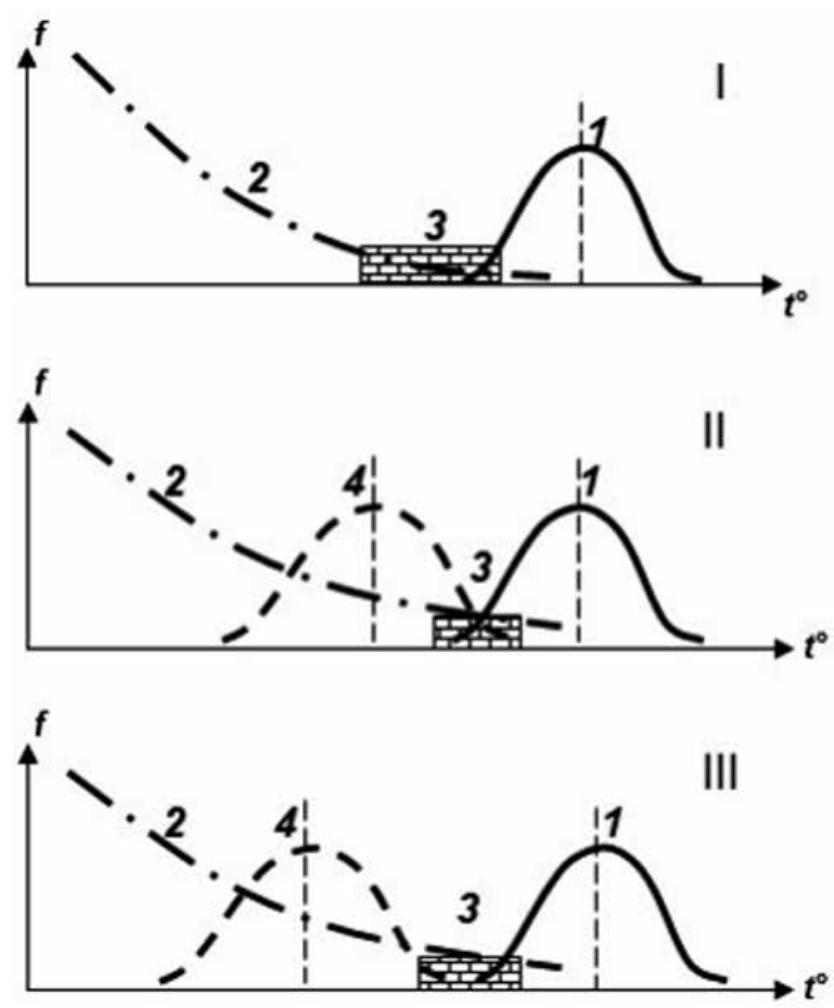

Рис. 3. Схема регуляции температуры тела в период полной активности (по материалам [48, 95]). $t^{\circ}$ - температуры тела, $f$ - относительная интенсивность терморегуляционных реакций. I - схема организации регуляции температуры тела в период полной активности у рыб (Pisces), амфибий (Amphibia) и некоторых рептилий (Reptilia: Ophidia, Gekkota, Chelonia, Crocodilia). II - вариант организации терморегуляторных реакций у ряда групп рептилий (Reptilia: Iguanomorpha, Scincomorpha, Anguinomorpha). III - варианты организации терморегуляторных реакций ряда групп рептилий (некоторые пустынные Agamidae, Iguanidae, Scincidae и др.). 1 - проявление реакций избегания высокой температуры; 2 - направленность реакций на максимизацию температуры тела; 3 - зона термостабилизации; 4 - проявление реакций избегания низких температур

ЭТР 2. Реакция поддержания четкой нижней границы температуры тела (рис. 3-4). Это регулятор нижней границы температуры тела в состоянии полной активности.

ЭТР 3. Реакция «максимизации» температуры тела (рис. 3-2). Проявление этого механизма выражается в стремлении к повышению температуры вплоть до верхней границы. Эта реакция проиллюстрирована, в частности, описанием стратегии терморегуляции у обыкновенных гадюк Pelias berus в Карелии [11, 12]. Важно учесть, что эта реакция сильно угнетается стрессовыми воздействиями. Поэтому у рептилий, у которых не проявляется механизм ЭТР 2, но выражен механизм ЭТР 3, нижняя граница температуры тела при полной активности выражена не очень четко и часто может иметь большой разброс. При сильном стрессе реакции ЭТР 3 могут даже вообще не проявляться. Именно такая ситуация зарегистрирована в работе по изучению термальных предпочтений у изменчивого олигодона Oligodon taeniolatus, что привело автора к ошибочному выводу о том, что таких предпочтений у этих змей вообще нет [8]. 
2) Схема стабилизации температуры тела или его отдельных частей на высоком уровне, исходя из потребностей физиологических функщий и органов.

ЭТР 4. Реакция стабилизации температуры тела (часто - отдельных его частей) на высоком уровне, исходя из потребностей физиологических функций и органов (при переваривании пищи, в некоторых стадиях гаметогенеза, при беременности и т. п.).

3) Схема регуляции температуры тела в периоды неактивного состояния призвана реализовать физиологически необходимую сезонную динамику температуры тела, то есть регулировать сезонную изменчивость температур ночного покоя, температуры при гибернации и эстивации.

ЭТР 5. Реакция поддержания температуры тела на определенном уровне или в определенном диапазоне в периоды неактивного состояния при разных фазах сезонного цикла. Рептилии выбирают разные уровни температур ночного покоя в разные сезоны [110 и др.], регулируют продолжительность тепловой фазы в течение суток и т. п. Также они произвольно регулируют температуры тела при «зимней спячке». Это показано у щитомордников Gloydius blomhoffi в естественных зимовках в Приморском крае [13]. Выбор температур также наблюдался у среднеазиатских гюрз в созданных ими искусственных зимовках, располагавшихся в уличных вольерах Ташкентского змеепитомника. К сожалению, до сих пор не известно, какими механизмами эта терморегуляционная реакция осуществляется.

У рептилий можно выделить некоторые общие, схематизированные модели терморегуляции. В основном это модели регуляции температуры тела в полной активности, поскольку организация механизмов терморегуляции в неактивном состоянии, как отмечено выше, остается непонятной.

Все модели терморегуляции рептилий складываются из нескольких «конструктивных блоков» (рис. 4).

Четкая верхняя граница температуры полной активности формируется за счет ЭТР 1 (рис. 4: 4).
Четкая ниюняя граница температуры полной активности формируется за счет ЭТР 2 (рис. 4: 3-2).

"Плавающая" ниюсня граница температуры полной активности формируется за счет ЭТР 3 (рис. 4: 3-1). Она - компромисс между действием реакции максимизации температуры тела, с одной стороны, и противодействием потребностей животного в питании, охране территории, размножении и т. п., стрессами - с другой.

Периодическая стабилизация температуры тела (или его отдельных частей) на высоком уровне по физиологическим потребностям организма формируется за счет механизма регуляции, описание которого я не нашел в литературе. Очевидно только реальное наличие этого феномена.

Диапазон термостабилизации формируется взаимодействием верхнего и нижнего регуляторов температуры полной активности. При этом проявляются два варианта такого определения: снизу действует регулятор либо четкой нижней границы температуры полной активности (рис. 3, II и III), либо - «плавающей» нижней границы (рис. 3, I). В первом варианте диапазон термостабилизации будет иметь более или менее определенные границы, а его «ширина» будет формироваться положением границ относительно друг друга. Если границы расположены далеко друг от друга и их «чувствительности» почти не перекрываются, то модальная область диапазона термостабилизации будет шире (рис. 3, III), чем если границы расположены близко и их «чувствительности» сильно перекрываются (рис. 3, II), или если нижняя граница температур полной активности плавающая (рис. 3, I). А при стрессовых воздействиях диапазон термостабилизации может вообще не проявляться.

Температуры в период неактивного состояния, как отмечено выше, существуют как некий реальный показатель, но механизм их формирования пока неизвестен.

\section{Общие модели терморегуляции рептилий}

Bapианm I. Модель терморегуляции в целом подобна таковой, описанной для рыб (рис. 3, I). Она

\section{I}

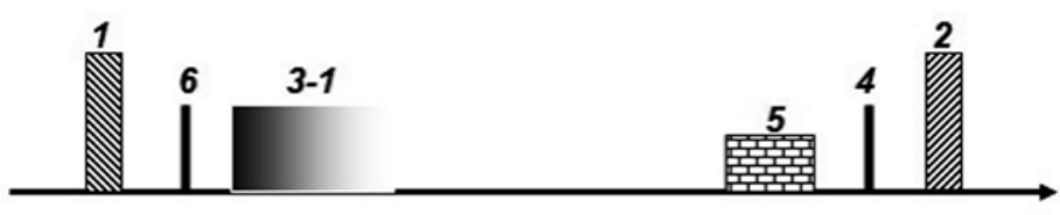

$t^{\circ}$

II

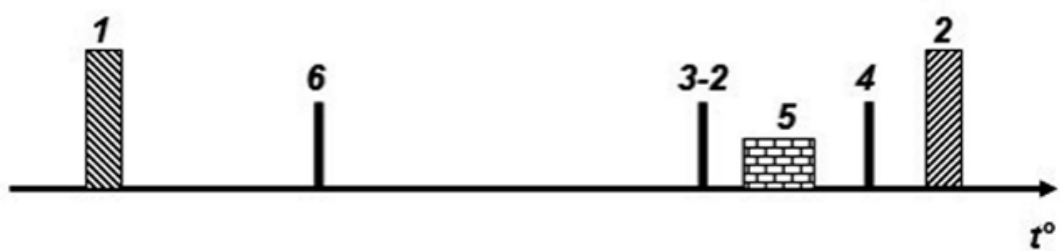

Рис. 4. Схема термофизиологических показателей у рептилий (по $[48,95]):$ I и II - варианты организации терморегуляции у рептилий (см. текст); 1 - критический минимум; 2 - критический максимум; 3-1 - вариант проявления плавающей нижней границы температуры полной активности; 3-2 - вариант проявления четкой нижней границы температуры полной активности; 4 - верхняя граница температуры полной активности; 5 - диапазон термостабилизации; 6 - температуры ночного покоя 
складывается из четкой верхней границы температуры полной активности, организованной посредством ЭТР 1, и «плавающей» нижней границы температуры полной активности, организованной посредством ЭТР 3 (реакции максимизации температуры тела). Диапазон термостабилизации часто существенно у́же диапазона температур полной активности и располагается в его верхней части. Нижняя граница диапазона термостабилизации вместе с нижней границей температуры полной активности зависит от многих обстоятельств, и при стрессовых воздействиях диапазон термостабилизации может вообще не проявляться. Хорошо проявляется периодическая стабилизация температуры тела (или его отдельных частей) на достаточно высоком уровне в соответствии с физиологическими потребностями организма.

Рептилий с таким вариантом организации терморегуляции мы назвали термонейтрально активными $[36,41,45]$. Он характерен для гаттерии Sphenodon punctatus (Rhinchocephalia), Gekkota, всех змей (Ophidia) и, скорее всего, для всех черепах (Chelonia) и крокодилов (Crocodilia). При полной активности они осваивают температурную зону, лежащую вблизи и ниже (иногда значительно) диапазона температур термостабилизации (рис. 3 I и 4 I). Мы применили название «термонейтрально активные рептилии» не потому, что они вообще индифферентны к температуре и терморегуляция у них слабо проявлена, а поскольку их полная активность непосредственно и неразрывно не связана с необходимостью все время удерживать температуру тела на постоянном и достаточно высоком уровне и может протекать в довольно широком диапазоне даже низких температур тела. В этом смысле их полная активность (а не жизнь в целом) более или менее термонейтральна. Но в определенные периоды в течение суток и сезона для осуществления ряда физиологических процессов им необходима высокая температура тела, и они в это время успешно терморегулируются и греются, хотя удовлетворение этих физиологических потребностей может быть не связано с активностью.

Настороженность в этой связи вызывают, например, крокодилы, поскольку некоторые данные [127 и др.] говорят о том, что их морфология и физиология могут значительно отличаться от таковой других животных, которых мы традиционно относим к Reptilia. Возможно, дальнейшее изучение филогении покажет, что это не единственная подобная группа (например, черепахи). Но о чешуйчатых в этом плане можно говорить достаточно уверенно.

Bapuaнm II. Модель терморегуляции складывается из четкой верхней границы температуры полной активности, организованной посредством ЭТР 1, и четкой нижней границы температуры полной активности, организованной посредством ЭТР 2, которые ограничивают диапазон температур полной активности. При низких температурах проявляется реакция максимизации температуры тела - ЭТР 3 (рис. 3, II).

Рептилий с таким вариантом организации терморегуляции мы назвали термостабильно активными $[36,41,45]$. Он характерен для Scincomorpha, Iguanomorpha и Anguinomorpha, Varanoidea. При полной активности они осваивают температурную зону, лежащую вблизи и немного выше диапазона температур термостабилизации (рис. $3 I I, 3 I I I$ и $4 I I$ ). У термостабильно активных рептилий полная активность связана с необходимостью постоянно поддерживать на более или менее высоком уровне температуру тела.

Различия между отмеченными выше двумя большими группами рептилий достаточно глубоки [48], они в значительной степени связаны с организацией терморегуляции в нервной системе, которая, видимо, является достаточно устойчивой характеристикой. Возможно, что схожесть механизмов терморегуляции внутри таких групп термонейтрально активных рептилий, как змеи, черепахи и крокодилы, - лишь проявление аналогии, а не гомологии структур и функций. Все это требует серьезного, дополнительного изучения.

Зато деление рептилий на термостабильно и термонейтрально активных имеет большое значение для правильного использования методик исследований и обработки материала в области термобиологии.

\section{4. Как и чем организован у рептилий комплекс термофизиологических показателей?}

Термофизиологические показатели характеризуют физиологическую, видоспецифичную норму реакции данного вида рептилий на температуру; описывают потенциальные пределы температурной выносливости и термальную зону активности рептилий; описывают полные, потенциально возможные диапазоны термальных характеристик; формируются и поддерживаются определенными регулирующими механизмами в центральной нервной системе [80]. Термофизиологические показатели, которые не формируются и не поддерживаются регулирующими механизмами в центральной нервной системе, являются характеристиками, которые произвольно сформированы исследователем и в реальности вообще не существуют. Учитывать это обстоятельство очень важно!

Исследования показали, что в нервной системе рептилий имеется ряд специальных, отдельных механизмов регуляции температуры. Это механизмы определения (регуляторы) верхней и нижней границы температур полной активности и ряд других $[12,48$, 74, 95 и мн. др.]. Именно эти механизмы регуляции температуры тела и их взаимодействие формируют и определяют наличие у рептилий таких термофизиологических показателей, как диапазоны температур полной активности и т. п. Необходимо обратить внимание на то, что специальные регуляторы в нервной системе рептилий призваны сформировать у них именно диапазон температур полной активности, а не просто диапазон температур тела, «зарегистрированных в течение сезона активности» [20, с. 5]. Этот последний показатель, упомянутый Н.А. Литвиновым [20], находится примерно в границах между критическими минимумом и максимумом. Он предложен очень авторитетным органом Commission for Thermal Physiology of the International Union of Physiological Sciences как «допустимый диапазон температур», но только температур среды (!) - «tolerated ambient temperature range» [91, с. 102], который важен в первую очередь для эндотермов и является по сути неким «диапазоном температурной толерантности» у эндотермных животных данного вида. Но он, естественно, не учитывает регуляцию температуры тела при важнейшем для жизнедеятельности пресмыкающихся (эктотермов) состоянии полной 
активности, на регуляцию которой и направлены специальные механизмы, сформированные в нервной системе рептилий.

Подробный разбор применимости разных показателей в термобиологии рептилий приведен нами в специальной публикации [80]. В результате этого анализа мы считаем действительными, функциональными, реально существующими следующие термофизиологические показатели: максимальная и минимальная температуры полной активности ограничивают диапазон температур полной активности ${ }^{1}$ (организуются и реализуются верхним и нижним регуляторами границ диапазона температур полной активности), диапазон температур термостабилизации (организуется и регулируется частично взаимодействием верхнего и нижнего регуляторов, частично - неизвестными еще нам физиологическими механизмами) - это термофизиологические показатели активности рептилий; критические максимум и минимум (определяются биохимическими закономерностями) - температуры термальной выносливости рептилий; температуры ночного покоя (определяются неизвестными еще нам физиологическими механизмами); диапазон суточных колебаний температуры тела и запас «температурной прочности» вида (определяются взаимодействием верхнего и нижнего регуляторов границ диапазона температур полной активности и температур ночного покоя). В данном наборе показателей все они имеют вполне определенные механизмы формирования в центральной нервной системе, в биохимических закономерностях и т. п. Поэтому мы выделяем именно такой набор термофизиологических показателей, важных для рептилий как высших эктотермных животных. При этом мы не входим в конфликт с решениями Commission for Thermal Physiology of the International Union of Physiological Sciences, поскольку, хотя наборы предлагаемых нами и Комиссией термобиологических характеристик существенно различаются, но это вполне закономерно и естественно, так как показатели эти относятся к разным группам животных, обладающих различными базовыми отношениями к регуляции температуры тела: у нас - к эктотермам, а у Комиссии - к эндотермам.

\section{5. Каковы важнейшие свойства набора термофизиологических показателей, полученных с помощью скорректированных методик?}

Набор термофизиологических показателей позволяет стандартизировать исследования и получать величины, «приведенные к единому знаменателю» и пригодные, таким образом, для корректных сравнений и анализа.

Наши собственные исследования на девяти видах рептилий, а также анализ большого количества

Ранее никто из исследователей не применял в качестве термобиологических показателей диапазон температур полной активности и диапазон термостабилизации. А именно их применение принципиально важно, потому что другие показатели (диапазон добровольных температур тела или просто диапазон температур тела, при котором рептилии встречаются в зоне активности, а также диапазон предпочитаемых или оптимальных температур тела) - абстрактные характеристики, не имеющие специальных организующих механизмов в центральной нервной системе, а следовательно, у них нет и строгой физиологической основы. литературных источников однозначно показал, что основные термофизиологические показатели у рептилий видоспецифичны и неизменны ни популяционно, ни географически, ни сезонно [38, 40, 48, 52, 53 и др.]. Этот комплекс неизменных, видоспецифичных характеристик термального (и не только) гомеостаза у рептилий назван нами «физиолого-экологической матрицей вида» - ФЭМ [79]. Описание ФЭМ является очень важной новацией, полученной исключительно благодаря новации методической. Этот комплекс имеет огромное значение, поскольку представляет собой цельное, стабильное «ядро», неизменную, видоспецифичную матрицу, которая, ввиду ее неизменности и стабильности, дает возможность понять и описать жесткие механизмы структурирования пространственно-временной суточной и сезонной активности рептилий в разных условиях среды обитания, их биотопического распределения и географического распространения, понять значение этих структур активности в регуляции внешними условиями физиологических процессов в организме рептилий, вносит коррективы в понимание явления адаптации и механизмов эволюции.

\section{6. Что такое термальные адаптации, и как они у рептилий организованы?}

До настоящего времени все работы по теме термальных адаптаций рептилий касались на самом деле не адаптаций как таковых, а отдельных термобиологических особенностей рептилий. В этих работах применялось понятие «адаптации», но само по себе явление адаптации почти не исследовалось. Так, даже специальная книга на эту тему [64] на самом деле касается именно термобиологии рептилий, но об адаптациях в ней практически нет ни слова. Изучение влияния температуры на разные физиологические функции и поведенческие реакции - безусловно важное направление исследований, но имеет лишь «касательное» отношение к явлению адаптации. Во всяком случае, если термобиологические особенности рептилий, влияние температуры на их физиологические процессы и можно считать адаптациями к среде, то это положение нужно специально изучить и доказать. Но это до нас мало кто делал [50].

Определений термина «адаптация» в литературе приводится много [7, 16, 59 и др.]. Но в любом случае это понятие функциональное, динамическое, выражающееся в сохранении или организации возможностей для успешного выживания особей, популяций и видов в данных или меняющихся условиях среды при допустимых энергетических затратах на жизнеобеспечение особей и воспроизводство популяций, для успешной конкуренции с другими видами.

«Термальные адаптации» - это морфологические свойства, биохимические, физиологические и поведенческие реакции, направленные на приспособление, на улучшение приспособленности организма животного, сообщества или вида к данным термальным условиям среды или на приспособление к новым, меняющимся условиям термальной среды (при изменении условий или при освоении новых биотопов, что тоже есть изменение условий).

Теперь можно подойти к рассмотрению проблемы термальных адаптаций. 
Примерами немногих работ, отразивших механизмы связи термобиологических характеристик рептилий с их экологией, являются статьи W.P. Porter и др. [120] и R. Нuеy [100]. При этом теоретическое обоснование описанного ими же механизма в этих статьях было недостаточным. В своем рассмотрении проблемы авторы предполагали априори их постоянство, неизменность в разные сезоны и в разных экологических условиях по ареалу. Но это важнейшее свойство осталось без обсуждения, без доказательства, как «интуитивно понятная» аксиома, принимаемая «по умолчанию». Тем не менее, надо отдать должное авторам этих статей - их работы оказались новаторскими. Но последователи этих ученых даже не обратили внимания на это важнейшее свойство, эти новации не были ими подхвачены.

В относительно недавнее время в литературе укоренились две пары терминов, описывающих степень проявленности терморегуляции у рептилий и/ или формы их адаптации к термальным условиям среды. Первая из них - это thermoregulators («терморегуляторы» - то есть животные, которые активно и эффективно регулируют температуру тела) и thermoconformers («термоконформеры» - то есть животные, которые не проявляют активных усилий по регуляции температуры тела, которая в этом случае практически пассивно следует за температурами среды [67 и др.]). Относительные термоконформеры среди рептилий, безусловно, существуют [61, 96, 99, $103,123,125,126,130$ и др.]. Но они именно «относительные», поскольку чаще всего такие виды почти не регулируют температуру тела в границах тех диапазонов температур, в которых они оказываются в природных условиях и которые при этом почти соответствуют эндогенно потребным температурам тела данных видов рептилий, и/или динамика температур среды обеспечивает эндогенно потребную динамику температуры тела без активного применения специальных регуляционных механизмов. Сам факт того, что терморегуляционные реакции у них не наблюдаются, - не проявление отсутствия терморегуляции или наличия какого-то специфического ее механизма, а лишь бо́льшая или меньшая степень редукции существующего стандартного механизма, связанная с особенностями физиологии и обитанием в тропических климатах, где температуры среды не опускаются слишком низко и/или не поднимаются слишком высоко, и где сезон таких «теплых» условий имеет в году большу́ю продолжительность (практически теплый сезон с температурами около $28-32{ }^{\circ} \mathrm{C}$ длится почти весь год).

Вторая пара терминов - thermal specialists (рептилии, которые удерживают температуру тела в узком диапазоне; близко к понятию «стенотермы») и thermal generalists (рептилии, температура тела которых находится в широком диапазоне, то есть они не так четко регулируют температуру тела; близко к понятию «эвритермы»). Однако и это разделение не дает сколь-нибудь важной информации, поскольку если, например, два разных вида рептилий удерживают температуру тела в достаточно узком диапазоне, но делают это за счет сильно различающихся эндогенных механизмов или вследствие того, что температуры среды в месте обитания подвержены слабым колебаниям, то мы имеем дело лишь с аналогией, базирующейся на феноменологии, а не с гомологией.
Строить же классификацию функциональных явлений на основе аналогичных характеристик, по крайней мере, не слишком корректно.

Адаптации как биологическое явление могут иметь разную направленность и обусловленность:

к определенным абиотическим факторам внешней среды;

к изменениям условий среды;

к конкретным географическим и макроклиматическим комплексам;

к появлению нового, сильного, определенного возмущающего фактора внешней среды;

к условиям внешней среды в связи с появлением нового, отличного от прежнего, внутреннего состояния организма;

к различным условиям внешней среды, когда важным для благополучной жизнедеятельности требованием организма является сохранение стабильности комплекса «ключевых» физиологических параметров гомеостаза (физиолого-экологической матрицы - ФЭМ);

в связи с появлением необходимости и/или возможности освоения новых условий внешней среды;

в связи с необходимостью изменения в активности и направленности двигательной и психической деятельности;

и т. Д., и т. п.

О каком же типе адаптаций можно говорить при исследовании термальных адаптаций?

В наших последних работах $[50,80]$ мы подробно разбирали эту тему и пришли к однозначному выводу: основная часть термальных адаптаций рептилий направлена на сохранение стабильности комплекса «ключевых» физиологических параметров термального гомеостаза. Этот вывод базируется на описанном нами наличии у рептилий комплекса стабильных, популяционно, географически и сезонно неизменных термофизиологических показателей термального гомеостаза.

Каким образом реализуются эти адаптации? Все имеющиеся материалы наших исследований [39, 48, $50,80]$ и многочисленные научные публикации говорят о том, что большинство физиологических реакций являются температурно зависимыми, проявляя, таким образом, не связанные с адаптацией к условиям среды свойства биохимических соединений и физиологических систем, которые вряд ли могут сильно повлиять на тепловой баланс тела рептилий, на регуляцию его температуры.

Мало того, ряд физиологических процессов, биохимических и поведенческих реакций протекают в оптимальном режиме именно при температурах, близких к диапазону термостабилизации $[48,56-58,62$, $63,72,73,78,84,87,92,93,100,106-108,110,134$ и мн. др.]. Но также известно, что температурный оптимум многих важных физиологических функций не совпадает с избираемыми данными животными температурами тела, с температурой термостабилизации [65, 97, 101 и др.]. То же можно сказать и о температурных оптимумах работы различных ферментов. Так, у многих рыб и беспозвоночных активность ферментов оказывается максимальной при температуре на $10-40^{\circ}$ выше той, при которой они в природе живут 
и которую избирают в эксперименте $[1,14,15,17,22$ и др.]. И у рептилий тоже в некоторых случаях температурные оптимумы ряда ферментов оказываются выше той температуры, которую животное вообще может вынести [107].

Таким образом, однозначно утверждать, что термальные биохимические и физиологические характеристики у эктотермов вообще и у рептилий в частности адаптивно направлены, будет просто неверно.

Две наши недавно опубликованные работы полностью или частично посвящены анализу того, являются ли физиологические реакции и связанные с ними закономерности адаптивно направленными [50, 80]. Наше заключение по этому поводу таково: значительная часть физиологических реакций и связанных с ними закономерностей температурно зависимы, но при этом не являются адаптациями к термальным условиям среды.

Поскольку основная направленность адаптивных реакций рептилий проявляется в стремлении сохранить неизменность видоспецифичных, термофизиологических показателей термального гомеостаза [50, 80], встает вопрос о том, за счет чего эта направленность реализуется. Наши специальные исследования показали, что термальный гомеостаз поддерживается в основном посредством поведенческой модификации пространственно-временных структур суточной и сезонной активности. Это, в частности, продемонстрировано на примере изучения термобиологии и экологии ряда видов ящериц и змей в разных частях их ареалов и в разные сезоны [2, 32-34, 37, 48, 50, 54 и др.]. Эти и другие примеры иллюстрируют механизм формирования однозначной, «рамочной» пространственно-временно́й структуры суточной активности у рептилий: исходя из конкретных метеоусловий места обитания, комплекса неизменных, видоспецифичных характеристик термального гомеостаза и видоспецифичных механизмов регуляции температуры тела, рептилии данного вида в данных условиях среды могут иметь единственно возможную, «рамочную» пространственно-временную структуру суточной активности. Поскольку все эти условия однозначно определяют возможности суточной активности рептилий данного вида в каждый конкретный день в течение года, то это значит, что они также однозначно определяют у рептилий и «рамочную» пространственно-временную структуру сезонной активности [48].

В течение многих лет мы изучали биологию среднеазиатской эфы Echis multisquamatus. Мы показали, что сезонные изменения климатических условий в биотопах эф закономерно и почти однозначно меняют структуру их пространственно-временной суточной активности, что регулирует проявления разных этапов сезонного полового цикла и сезонного цикла питания [54].

Такая или подобная «механика» регуляции характерна и для других рептилий.

Следует особо остановиться на такой важной характеристике, как сумма «эффективных температур» $(\Sigma \mathrm{Te})$ или «градусо-дни», значение которой изучали на разных группах животных [9, 10, 23, 113, 117 и др.]. В англоязычной литературе этот показатель называют degrees days (DD) heat units (тепловые единицы) $[66,68,69,119,133,137]$. Ряд исследований были проведены на рептилиях [109, 119, 133 и др.].

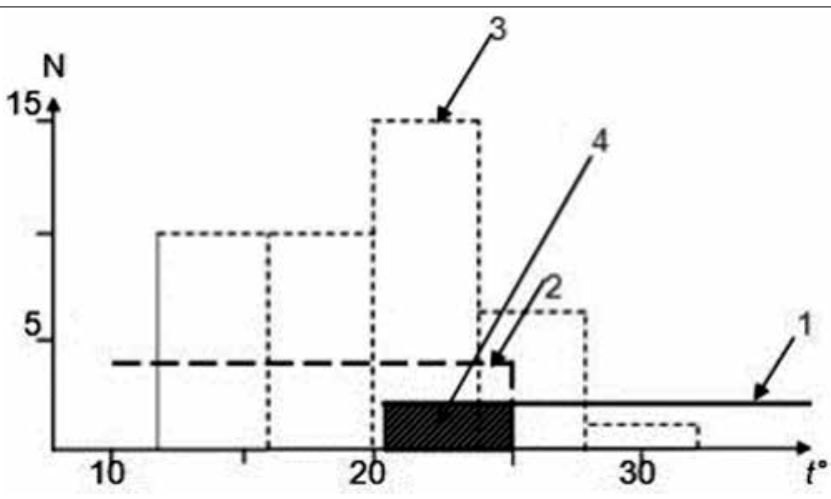

Рис. 5. Микроклиматические условия, определяющие сроки протекания половой активности у среднеазиатской эфы (по [54]). N - частота встреч эф (в \% от общего числа встреч); $t^{\circ}$ температура почвы на глубине 20 см; 1 - температура почвы в норах, при которой эфы могут свободно передвигаться по поверхности (иметь длительный период ТНП); 2 температура почвы в норах, при которой может протекать гаметогенез; 3 - частота встреч эф на поверхности в светлое время суток в зависимости от температуры почвы в норах (в \% от общего числа встреч); 4 - интервал температур почвы в норах, при котором возможна половая активность

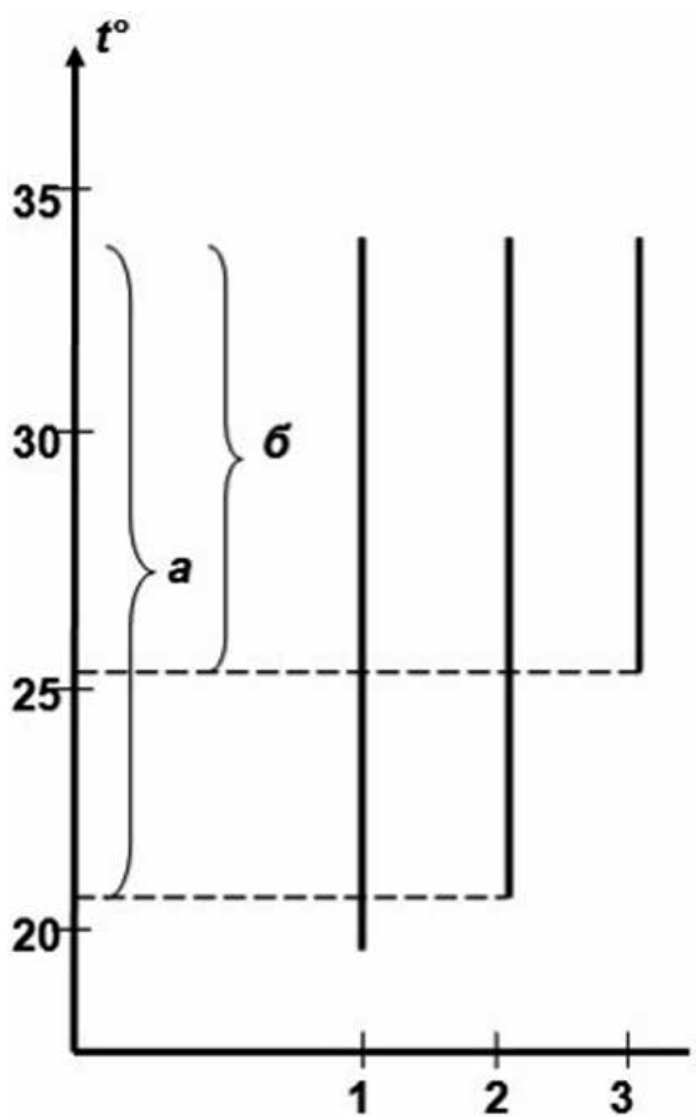

Рис. 6. Микроклиматические условия, определяющие время протекания пищевой активности у среднеазиатской эфы (по [54]). t $^{\circ}$ - температура почвы на глубине 20 см; 1 - температура почвы в норах, при которой возможно переваривание пищи; 2 - температура почвы в норах, при которой возможна охота; 3 - температура почвы в норах после завершения половой активности; а - интервал температур почвы в норах, при которых возможно питание не размножавшихся в данный сезон особей, б - интервал температур почвы в норах, при котором возможно питание размножавшихся в данный сезон особей 
Наши расчеты количества теплоты $\left(\Sigma \mathrm{T}_{\mathrm{e}}\right)$ для разных видов змей по специально модернизированным методикам [48] показали, что для разных видов $\Sigma \mathrm{T}_{\text {e }}$ довольно сильно различаются - у теплолюбивых видов этот показатель более чем в 3 раза выше, чем у холодолюбивых. Это значит, что для завершения одних и тех же процессов теплолюбивым видам надо значительно больше времени, чем холодолюбивым.

Мало того, у каждого вида рептилий, видимо, есть критическое значение $\Sigma \mathrm{T}$, ниже которого реализация, в частности, репродуктивного цикла невозможна. Это обстоятельство будет являться серьезным препятствием к распространению животных данного вида в регионы с более холодным климатом. При этом ряд видов, обитающих в горах или в северных районах, не всегда могут набрать за год $\Sigma \mathrm{T}_{\mathrm{e}}$, достаточную для завершения, например, полового цикла, и размножение у них происходит не ежегодно, что продемонстрировано на примере обыкновенной гадюки Pelias berus [114].

При наличии материалов исследований по термобиологии некоторого вида рептилий и по климатическим характеристикам разных географических регионов можно с большой степенью достоверности вычислить структуру суточной и сезонной активности этих животных и сумму эффективных температур для них в данных местах. А если знать критический минимум суммы эффективных температур для данного вида, можно, например, определить, в каких районах он сможет жить, а в каких - нет.

Таким образом, на основании всего сказанного выше можно заключить, что основной механизм индивидуальных термальных адаптаций рептилий выражается не в пластичности термофизиологии, а - в первую очередь - в тонкой поведенческой подстройке пространственно-временной структуры суточной и сезонной активности, направленной на сохранение в неизменности в любых условиях среды комплекса основных термофизиологических показателей гомеостаза.

\section{7. В чем может проявляться у рептилий эволюция термобиологической сферы?}

Мы уже показывали выше, что при изменении условий среды рептилии данного вида стараются, благодаря поведенческим модификациям пространственно-временной структуры активности, сохранить неизменным комплекс основных видоспецифичных термофизиологических характеристик. И весь опыт исследовательской работы подтверждает, что этот механизм у рептилий развит очень сильно: с одной стороны, рептилии данного вида могут жить только в тех условиях среды, в которых поведенческие модификации пространственно-временной структуры активности позволяют комплексу основных видоспецифичных термофизиологических характеристик оставаться неизменным; с другой стороны, рептилии, обладая одинаковыми термофизиологическими характеристиками, могут населять регионы с разными природно-климатическими условиями, а рептилии с разными термофизиологическими показателями - одинаковые [48]. А из этого логично следует другой, несколько неожиданный вывод: важнейшая направленность индивидуальных тер- мальных адаптаций - вывести комплекс видоспецифичных термофизиологических характеристик из-под влияния отбора. Таким образом, вряд ли эволюция термобиологической сферы рептилий может проявляться в адаптивно направленных изменениях «настроечных», «штатных» значений физиологических, терморегулирующих констант в структуре механизма регуляции температуры тела в центральной нервной системе.

Тем не менее, каким-то образом термофизиологические показатели некоторых (не всех) видов рептилий, населяющих разные природно-климатические зоны, часто оказываются сопряженными с природно-климатическими условиями мест обитания: например, температуры тела у многих пустынных видов (но не у всех!) действительно оказываются выше, чем у обитателей более прохладных зон. Как же это происходит, если направленность индивидуальных адаптаций противодействует отбору термофизиологических характеристик в сторону их адаптаций к условиям среды? Ни мы, ни другие исследователи не дают пока ответа на этот вопрос. Никто сейчас не может сказать, под влиянием каких факторов меняются «настроечные», «штатные» значения физиологических, терморегулирующих констант в структуре механизма регуляции температуры тела в центральной нервной системе. Эта важная проблема требует дополнительного изучения.

\section{3. РЕПТИЛИИ В СИСТЕМЕ ЖИВОТНОГО МИРА}

Существуют два кардинальных направления реализации важнейшего эволюционного принципа - направленности на повышение температуры тела в эволюции позвоночных животных: это эктотермные и эндотермные животные.

У эктотермных животных стабилизация температуры тела на высоком уровне происходит лишь периодически и, в основном, за счет внешних источников тепла. Регуляторные механизмы обеспечения жизнедеятельности в разных климатических условиях связаны, в основном, с поведенческими терморегуляционными реакциями и модификациями пространственно-временной структуры активности. Цель этих регуляторных реакций - поддержание соответствующей суточной и сезонной динамики температуры тела, при которой температура тела периодически (по мере необходимости - экологической, физиологической) поддерживается в некотором нешироком диапазоне высоких температур.

У эндотермов появление специфических, эндогенных, биохимических реакций термогенеза [45, 60 и мн. др.], то есть эндогенных источников тепла, позволило им быть относительно независимыми от климатических условий среды. Регуляторные механизмы обеспечения жизнедеятельности в разных климатических условиях связаны, кроме поведенческих реакций, с подстройкой уровня метаболических процессов, физиологическими реакциями сердечнососудистой системы, водным обменом и т. п. Цель этих регуляторных реакций - постоянно поддерживать температуру тела на высоком уровне.

Именно под эти «генеральные» особенности биологии, под эти важнейшие требования «подстраивается» в эволюции вся морфология, вся физиология 
позвоночных эктотермов (рыб, амфибий и рептилий, которые представляют собой более или менее единое эволюционное направление) и эндотермов (млекопитающих и птиц, которые в эволюции имеют самостоятельные корни). На этом основании можно утверждать, что эктотермы и эндотермы - два кардинальных направления эволюции позвоночных животных. Каждое из них формировалось самостоятельно, развивая собственные морфофункциональные системы. И в каждом направлении определенные группы достигли наивысшего развития.

Среди эндотермов максимального развития достигли млекопитающие.

Среди эктотермов на вершине этого направления оказались рептилии. По уровню морфофизиологического развития они стоят существенно выше рыб и амфибий. Это проявляется в развитии опорно-двигательной, кровеносной, дыхательной, пищеварительной, нервной и других систем организма. Они обладают достаточно сложным и разнообразным индивидуальным поведением. Терморегуляционные реакции разного уровня достигают у рептилий безусловного совершенства, что проявляется в усилении относительной независимости суточной и сезонной динамики температуры тела от динамики климатических условий среды.

Рептилии на пути эволюционного развития биологии эктотермов достигли удивительной эффективности. С одной стороны, они поддерживают необходимую для их физиологии суточную и сезонную динамику температуры тела, с другой - осуществляют стабилизацию температуры тела на высоком уровне. Но источником тепла для них, в основном, являются энергетически «даровые» внешние факторы, стабилизация происходит лишь периодически, только когда повышение температуры тела является физиологически необходимым. В периоды ночного покоя и др. энергия на поддержание ее высокого уровня не тратится совсем. Таким образом, система поддержания температуры тела у рептилий является энергетически эффективной и экономной.

С учетом всех упомянутых здесь, а также и других обстоятельств рептилий можно считать вершиной эволюционного направления на развитие эктотермных позвоночных, то есть высшими эктотермами.

У эндотермов поддержание температуры тела на высоком уровне практически постоянное. Высокая температура тела поддерживается у них не только в периоды активности и интенсивного протекания разных физиологических процессов, но и в покое, во сне и т. п. Это сопряжено со значительными энергетическими затратами, которые не всегда энергетически оправданы, то есть они недостаточно энергетически эффективны и экономны.

Следовательно, у рептилий (как высших эктотермов) в эволюции сформировалась однозначно более энергетически экономная система обеспечения жизнедеятельности, чем у эндотермов. Для них это важно, поскольку их морфофункциональное развитие все-таки существенно ограничивает их активность, приток энергии и т. п. При этом она достаточно экологически успешная и конкурентоспособная, что позволяет этим животным заселять почти все известные природные зоны, за исключением полярных шапок и заснеженных высокогорий, не говоря уже об их бурном развитии в геологическом прошлом Земли.
У млекопитающих (как высших эндотермов) в эволюции сформировалась такая система обеспечения жизнедеятельности, которая однозначно выигрывает у эктотермов в плане конкурентных экологических преимуществ (возможность заселять холодные климатические зоны, недоступные для эктотермов, - приполярные области и снежные высокогорья, возможности бо́льшей двигательной активности, бо́льшей энергообеспеченности и бо́льшей выносливости, позволяющие получать реальные конкурентные преимущества, и т. п.) $[45,48]$. То, что, максимально развив преимущества эндотермного типа развития, они проявили бурную эволюционную радиацию, сформировав огромное количество новых таксономических форм, явно говорит об их конкурентных экологических преимуществах и успешности группы в целом.

Особая проблема - попытки сравнить значимость («вес») бо́льшей энергетической эффективности эктотермов и экологические преимущества эндотермов. Вряд ли возможно предполагать, что если даже конкурентные преимущества «весят» больше, это даст возможность эндотермам, как более конкурентоспособным, полностью заместить эктотермов в природе. Иллюстрацией этой мысли может служить тот факт, что эктотермы в ряде природных зон (например, в пустынях) более разнообразны (и, возможно, более многочисленны), чем эндотермы. Просто в разных природных зонах преимущества получают группы животных с разными физиологическими особенностями: в одних - эндотермы, в других - эктотермы.

Таким образом, эктотермы и эндотермы реализуют направленность на стабилизацию высокой температуры тела в двух разных эволюционных направлениях: эктотермы - преимущественно по пути развития энергетической экономичности системы обеспечения жизнедеятельности, а эндотермы - по пути ее экологической конкурентоспособности. Оба направления в равной мере успешны, каждое - в своей области. Рептилии и млекопитающие - вершины каждого из этих направлений развития, в которых ключевые особенности обоих трендов развиты в максимальной степени. Следовательно, современные рептилии - высшие эктотермные животные, а млекопитающие - высшие эндотермные. И мы не рискнули бы утверждать, что какое-то из этих направлений эволюционно более «успешное», даже учитывая бо́льшую цефализацию млекопитающих и лучшее развитие у них высшей нервной деятельности, поскольку все равно каждое из них максимально успешно в своих условиях среды, реально существующих сейчас на нашей Земле.

\section{4. ОСНОВНАЯ ПАРАДИГМА ТЕРМОБИОЛОГИИ РЕПТИЛИЙ (термобиологический диагноз рептилий)}

Представления об основах термобиологии рептилий в самом сконцентрированном виде можно сформулировать в ряде основных тезисов.

Рептилии - высшие эктотермные животные.

Регуляция температуры тела у рептилий направлена в основном на поддержание определенной суточной и сезонной динамики температуры тела. 
В рамках реализации эволюционного принципа стабилизации высокой температуры тела в эволюции позвоночных рептилии стремятся поддерживать в течение более или менее продолжительного времени в сутках (и в течение сезона) высокую температуру тела (в зависимости от вида от $26-27$ до $40-45^{\circ} \mathrm{C}$, чаще всего - около $30-35^{\circ} \mathrm{C}$ ) и делают это в основном за счет использования тепловых факторов внешней среды, применяя с этой целью комплекс разнообразных и тонко настроенных поведенческих реакций.

Механизмы терморегуляции в нервной системе и проявления активности определяют термофизиологические характеристики, которые по сути - «штатные» значения температуры тела, сохраняющиеся в памяти системы и лежащие в основе терморегуляции. Это - терморегулирующие характеристики, которые определяют для данного вида рептилий: a) пределы полных, потенциально возможных, не ограниченных экологическими или другими причинами диапазонов полной активности, температурных предпочтений и выносливости; б) уровни термостабилизации, а те, в свою очередь, определяют формы активности и терморегуляционного поведения, а также термоэкологические характеристики, показывающие варианты экологических адаптаций.

В отличие от ситуации с эндотермными животными, у рептилии нет единого, «штатного» значения переменной (температуры тела), которую они поддерживают благодаря реакциям обратной связи. У них можно выделить несколько элементарных терморегуляционных реакций (ЭТР). Большинство из них функционально представляет собой регулятор температуры тела, либо определяющий верхнюю или нижнюю границу температуры тела при полной активности, либо стабилизирующий температуру отдельных частей тела на каком-то определенном уровне. В основе каждого такого регулятора лежит свое, закрепленное, «штатное» значение температуры, которое, благодаря реакциям обратной связи (в основном поведенческим), не позволяет температуре тела в период полной активности либо подниматься выше одного «штатного» уровня, либо опускаться ниже другого «штатного» уровня, либо стабилизироваться около третьего «штатного» уровня. Из этих ЭТР формируется некоторое количество более сложных терморегуляционных блоков, из которых, в свою очередь, как из кирпичиков, складываются две основные общие модели терморегуляции разных групп рептилий.

Активно используя и развивая поддерживаемую физиологическими реакциями сильную связь температуры тела с термальными, «погодными» («оперативными», микроклиматическими) факторами среды, рептилии благодаря прежде всего развитому комплексу поведенческих регуляторных реакций ослабляют зависимость своей жизнедеятельности от климатических (макроклиматических) условий места обитания.

У рептилий имеется комплекс «базовых», стабильных, неизменных, видоспецифичных термофизиологических (терморегулирующих) характеристик, определяемых, прежде всего, структурой терморегуляционного механизма в нервной системе. Этот комплекс не подвержен внутривидовой (географической, популяционной, сезонной) изменчивости. На его основе формируется стабильная, неизменная, видоспецифичная «матрица», которая во многом обусловливает связь жизнедеятельности данного вида рептилий с климатическими условиями среды.

Индивидуальные и популяционные адаптации к среде обитания происходят не за счет адаптивной модификации термофизиологических характеристик, а за счет тонкой (в основном - поведенческой) подстройки пространственно-временных структур суточной и сезонной активности, стабильным «шаблоном» для которой служит «матрица» неизменных, видоспецифичных термофизиологических характеристик.

Поскольку «матрица» является видоспецифичным и неизменным комплексом физиолого-экологических характеристик, то в любых биотопах с конкретными климатическими условиями рептилии данного вида могут иметь единственно возможный, «рамочный» вариант пространственно-временной структуры суточной и сезонной активности.

Стабильная, термофизиологическая, терморегуляторная «матрица» через модификацию пространственно-временных структур сезонной активности также регулирует течение сезонных физиологических циклов питания и размножения.

Этот единственно возможный для рептилий данного вида в данных климатических и экологических условиях «рамочный» вариант пространственно-временной структуры суточной и сезонной активности, формируемый стабильной терморегуляторной «матрицей», однозначно определяет в данных условиях среды количество теплоты, которое может получить организм пресмыкающегося за год. Критерием адаптивных возможностей является то, насколько единственно допустимая для данного вида в данных условиях пространственно-временная структура сезонной активности позволяет или не позволяет данному виду набрать то количество теплоты, которое дает возможность реализовать все необходимые для него в течение годового цикла физиологические процессы, обеспечивающие выживание индивидуального животного и популяции.

В соответствии с двумя общими моделями терморегуляции рептилии делятся на две большие группы: термонейтрально и термостабильно активные.

Термонейтрально активные рептилии в период полной активности осваивают диапазон температур тела, лежащий как вблизи диапазона термостабилизации, так и существенно ниже его, то есть при полной активности, в отдельные периоды, когда температура тела оказывается существенно ниже диапазона термостабилизации, они могут быть вообще не заняты терморегуляцией. Термонейтрально активными являются все Rhinchocephalia, Gekkota, а также все змеи (Serpentes); скорее всего, к этой группе относятся также все черепахи (Chelonia) и крокодилы (Crocodilia).

Термостабильно активные рептилии в период полной активности осваивают диапазон температур тела, лежащий вблизи диапазона термостабилизации, то есть при полной активности рептилии постоянно поддерживают уровень температуры тела близким к диапазону термостабилизации (постоянно терморегулируются). Термостабильно активными являются все ящерицы, относящиеся к Scincomorpha, Anguinomorpha и Iguanomorpha.

Эктотермы реализуют направленность на стабилизацию высокой температуры тела преимущественно 
по пути развития энергетической экономичности и эффективности, в некоторой степени - в ущерб ее экологической конкурентоспособности (преимуще- ственно развиваемой у эндотермов). Это направление наиболее полно развито именно у рептилий как высших эктотермов.

\section{Литература}

\section{Список русскоязычной литературы}

1. Ананичев АВ. Пищеварительные ферменты рыб и сезонная изменчивость их активности. Биохимия. 1959;24(6):1033-40.

2. Боркин ЛЯ, Черлин ВА, Басарукин АM, Маймин МЮ. Термобиология дальневосточного сцинка (Eumeces latiscuttatus) на острове Кунашир, южные Курильские острова. Современная герпетология. 2005;3/4:5-28.

3. Гражданкин АВ. Особенности морфологии кожного покрова наземных рептилий в связи с терморегуляцией. Зоологический журнал. 1974;53(12):1894-7.

4. Гражданкин АВ. Морфологические особенности кожных покровов рептилий в связи с экологией и терморегуляцией. В кн.: Вопросы герпетологии. Материалы Четвертой Всесоюзной герпетологической конференции; 1977 февраль; Ленинград; 1977. С. 71-2.

5. Гражданкин АВ. Роль испарительной кожной влагоотдачи в терморегуляции наземных пустынных рептилий. В кн.: Вопросы герпетологии. Материалы Пятой Всесоюзной герпетологической конференции; 1981 сентябрь; Ашхабад; 1981a. С. 42.

6. Гражданкин АВ. Кожная влагоотдача у пустынных птиц и рептилий. Зоологический журнал. 1981б;60(2):265-70.

7. Дедю ИИ. Экологический энциклопедический словарь. Кишинев: Главная редакция Молдавской советской энциклопедии; 1989.

8. Доценко ИБ. Морфологические признаки и экологические особенности Oligodon taeniolatus (Serpentes, Colubridae). Вестник зоологии AH УCСР. 1984;(4):23-6.

9. Иванов 3В. Жизнь насекомых. М.: Сельхозгиз; 1959.

10. Кашкаров ДН. Основы экологии животных. М.-Л.: Госмедиздат; 1938.

11. Коросов АВ. Двухконтурная отрицательная обратная связь и модель терморегуляции гадюки. Ученые записки Петрозаводского государственного университета. Биология. 2008;(1):74-82.

12. Коросов АВ. Экология обыкновенной гадюки на Севере. Петрозаводск: Изд-во ПетрГУ; 2010.

13. Коротков ЮМ. Очерк экологии популяций змей Приморского края. Владивосток; 1978.

14. Коштоянц ХС. Основы сравнительной физиологии. Т. 1. М.-Л.: Изд-во АН СССР; 1950.

15. Коштоянц ХC, Коржуев ПА. Материалы к сравнительной физиологии пищеварительных ферментов. I: Трипсин холоднокровных и те- плокровных животных, температурный оптимум и теплоустойчивость их. Зоологический журнал. 1934;13(1):71-82.

16. Краткий толковый психолого-психиатрический словарь. http://dic.academic.ru/searchall. php

17. Кузьмина ВВ. Общие закономерности мембранного пищеварения у рыб и его адаптивная перестройка. Автореф. дисс. ... докт. биол. наук. М.: Ин-т эволюц. морфол. и экол. животных АН СССР; 1986.

18. Леках ВА. Ключ к пониманию физиологии: Учебное пособие. М.: УРСС; 2002.

19. Либерман СС, Покровская НВ. Материалы по экологии прыткой ящерицы. Зоологический журнал. 1943;22(2):247-56.

20. Литвинов НА. К вопросу об оценке температуры тела рептилий, ее соотношении с внешней температурой и адаптивности размеров и окраски. Принципы экологии. 2015;4(1):416.

21. Меницкий ДН. Принципы саморегуляции функциональных систем. В кн.: Судаков КВ, ред. Системный анализ механизмов поведения. М.: Наука; 1979.

22. Морев ЮБ, Смаилова ТС. Усвояемость пищи червями Tubifex tubifex (Müller, 1773) (Oligochaeta). Гидробиологический журнал. 1987;23(2):67-71.

23. Наумов НП. Экология животных. М.: Высшая школа; 1963.

24. Рюмин АВ. Температурная чувствительность позвоночных животных и биологический путь происхождения теплокровных форм. Сб. студ. научных работ МГУ.1939(6):5584.

25. Рюмин АВ. Значение температуры в онтогенезе и филогенезе животных. Успехи современной биологии. 1940;12(3):504-15.

26. Слоним АД. Животная теплота и ее регуляция в организме млекопитающих. Л.: Наука; 1952.

27. Слоним АД. Экологическая физиология животных. М.: Высшая школа; 1971.

28. Слоним АД. Учение о физиологических адаптациях. В кн.: Экологическая физиология животных. Т. 1. Общая экологическая физиология и физиология адаптаций. Ленинград: Наука; 1979. С. 79-182.

29. Слоним АД. Температура среды обитания и эволюция температурного гомеостаза. В кн.: Физиология терморегуляции. Л.: Наука; 1984. С. $378-440$.

30. Слоним АД. Физиология терморегуляции. Л.: Наука; 1984. 
31. Слоним АД. Эволюция терморегуляции. Л.: Наука; 1986.

32. Ушаков БП. Цитофизиологический анализ приспособления рептилий к высоким температурам пустыни. Вопросы цитологии и общей физиологии. М.-Л.; 1960. С. 355-67.

33. Целлариус ЕЮ, Целлариус АЮ. Температурные условия активности серого варана (Varanus griseus, Reptilia, Sauria). Зоологический журнал. 1997;76(2):206-11.

34. Целлариус АЮ, Черлин ВА, Меньшиков ЮГ. Предварительное сообщение о работах по изучению биологии Varanus griseus (Reptilia, Varanidae) в Средней Азии. Герпетологические исследования. Ленинград: ЛИСС; 1991;(1):61103.

35. Черлин ВА. Условия влажности в местах обитания песчаной эфы (Echis multisquamatus) в Южной Туркмении. В кн.: Вопросы герпетологии. Авторефераты докладов пятой Bceсоюзной герпетологической конференции; Ленинград; 1981. С. 149-50.

36. Черлин ВА. Способы адаптации пресмыкающихся к температурным условиям среды. Журнал общей биологии. 1983;44(6):753-64.

37. Черлин ВА. Зависимость щиткования змей рода Echis от климатических факторов. Зоологический журнал. 1983;62(2);252-8.

38. Черлин ВА. К термобиологии серого геккона (Cyrtopodion russowi), полосатой ящурки (Eremias scripta) и степной агамы (Trapelus sanguinolentus) в Восточных Каракумах. Известия Академии наук Туркменской ССР. Серия биологических наук. 1988;(5):36-43.

39. Черлин ВА. Интенсивность окисления митохондрий печени разных классов позвоночных животных при различных темпеpaтурах. В кн.: Тезисы научных сообщений IV съезда физиологов Узбекистана. Ташкент, 9-11 ноября 1988. Ташкент; 1988. с. 140-1.

40. Черлин ВА. Популяционные аспекты термальных адаптаций у пресмыкающихся. В кн.: Проблемы популяционной экологии земноводных и пресмыкающихся. М.: ВИНИТИ; 1989; c. $135-72$.

41. Черлин ВА. Стабилизация высокой температуры тела в эволюции позвоночных животных. Успехи современной биологии. 1990;109(3):440-52.

42. Черлин ВА. Методы исследований по термобиологии пресмыкающихся. Экология животных Узбекистана. Ташкент; 1991.

43. Черлин ВА. Термобиология рептилий. Общие сведения и методы исследований (руководство). СПб: Изд-во Русско-Балтийский информационный центр «БЛИЦ»; 2010.

44. Черлин ВА. Биологические основы содержания пресмыкающихся в неволе: тепловой фактор. СПб: Изд-во Русско-Балтийский информационный центр «БЛИЦ»; 2011.

45. Черлин ВА. Организация процесса жизни как системы. СПб: Изд-во Русско-Балтийский информационный центр «БЛИЦ»; 2012.

46. Черлин ВА. Термобиология рептилий. Общая концепция. СПб: Изд-во Русско-Балтийский информационный центр «БЛИЦ»; 2012.
47. Черлин ВА. Сложности и возможные ошибки при полевых исследованиях по термобиологии рептилий. В кн.: Современная герпетология: проблемы и пути их решения. Статьи по материалам докладов Первой международной молодежной конференции герпетологов России и сопредельных стран (Санкт-Петербург, Россия, 25-27 ноября 2013 г.). СПб: Зоологический институт РАН; 2013. с. 32-9.

48. Черлин ВА. Рептилии: температура и экология. Saarbrücken: Lambert Academic Publishing; 2014.

49. Черлин ВА. О статье С.С. Либерман и Н.В. Покровской по термобиологии прыткой ящерицы (1943 г.). Принципы экологии. 2014;3(3):25-32.

50. Черлин ВА. Тепловые адаптации рептилий и механизмы их формирования. Принципы экологии. 2015;4(1):17-76.

51. Черлин ВА, Музыченко ИВ. Термобиология и экология сетчатой ящурки (Eremias grammica), ушастой (Phrynocephalus mystaceus) и песчаной (Ph. interscapularis) круглоголовок летом в Каракумах. Зоологический журнал. 1983;62(6):897908.

52. Черлин ВА, Музыченко ИВ. К методике определения критического максимума температуры тела некоторых среднеазиатских ящериц. Известия Академии наук Туркменской ССР. Серия биологических наук. 1984;(5):73-6.

53. Черлин ВА, Музыченко ИВ. Сезонная изменчивость термобиологических показателей некоторых аридных ящериц. Зоологический журнал. 1988;67(3):406-16.

54. Черлин ВА, Целлариус АЮ. Зависимость поведения песчаной эфы, Echis multisquamatus Cherlin 1981 от температурных условий в Южной Туркмении. Фауна и экология амфибий и рептилий палеарктической Азии. Труды Зоологического Института АН СССР, т. 101. Л.: Наука; 1981: 96-108.

55. Черлин ВА, Целлариус АЮ, Громов АВ. К температурной биологии сцинкового геккона (Teratoscincus scincus) в Каракумах. Экология. 1983;(2):84-87.

56. Шмидт-Нильсен К. Животные пустынь. Л.: Наука; 1972.

57. Шмидт-Нильсен К. Физиология животных. Т. 1. М.: Мир; 1982.

58. Эккерт Р, Рэнделл Д, Огастин Дж. Физиология животных: Механизмы и адаптация: В 2 т. Т. 1. М.: Мир; 1991.

59. Энциклопедический словарь по психологии и педагогике. http://psychology_pedagogy. academic.ru

\section{Общий список литературы/Reference list}

1. Ananichev AV. [Digestive enzymes in fish and seasonal variability of their activity]. Biokhimiya. 1959;24(6):1033-40. (In Russ.)

2. Borkin LYa, Cherlin VA, Basarukin AM, Maymin MYu. [Thermal biology of far-east skink (Eumeces latiscuttatus) on Kunashir island, southern Kuril islands]. Sovremennaya Gerpetologiya. 2005;3/4:5-28. (In Russ.)

3. Grazhdankin AV. [Peculiarities of skin morphology in land reptiles as related toh thermoregu- 
lation]. Zoologicheskiy Zhurnal. 1974;53(12):1894-7. (In Russ.)

4. Grazhdankin AV. [Morphological peculiarities of skin in reptiles as elated to ecology and thermoregulation]. In: Voprosy Gerpetologii. Materialy IV Vsesoyuznoy Gerpetologicheskoy Konferentsii; Fevral' 1977. Leningrad; 1977. p. 71-2. (In Russ.)

5. Grazhdankin AV. [The role of evaporative cutaneous water loss in thermoregulation of land desert reptiles]. In: Voprosy Gerpetologii. Materialy V Vsesoyuznoy Gerpetologicheskoy Konferentsii; Sentyabr' 1981; Ashkhabad; 1981. p. 42. (In Russ.)

6. Grazhdankin AV. [Cutaneous water loss in desert birds and reptiles]. Zoologicheskiy Zhurnal. 1981;60(2): 265-70. (In Russ.)

7. Dedyu II. Ekologicheskiy Entsyklopedicheskiy Slovar [Ecological encyclopedic dictionary]. Kishinev: Glavnaya Redaktsiya Moldavskoy Sovetskoy Entsyklopedii; 1989. (In Russ.)

8. Dotsenko IB. [Morphological characters and ecological peculiarities in Oligodon taeniolatus (Serpentes, Colubridae)]. Vestnik Zoologii AN USSR. 1984;(4):23-6. (In Russ.)

9. Ivanov ZV. Zhizn' Nasekomykh [Life of Insects]. Moscow: Sel'khozgiz; 1959. (In Russ.)

10. Kashkarov DN. Osnovy Ekologii Zhivotnykh [Foundations of Animals Ecology]. Moscow-Leningrad: Gosmedizdat; 1938. (In Russ.)

11. Korosov AV. [Dual negative feedback model of thermoregulation in viper]. Uchenye Zapisk Petrozavodskogo Gosudarstvennogo Universiteta Biologiya. 2008;(1):74-82. (In Russ.)

12. Korosov AV. Ekologiya Obyknovennoy Gadiuki na Severe [Viper Ecology in the North]. Petrozavodsk: Izdadelstvo PetrGU; 2010. (In Russ.)

13. Korotkov YuM. Ocherk Ekologii Populiatsyi Zmey Primorskogo Kraya. [Essay on the Ecology of Snake Populations in Primorsky Kray]. Vladivostok; 1978. (In Russ.)

14. Koshtoyants KhS. Osnovy Sravnitelnoy Fiziologii. [Fundamentals of comparative physiology]. Moscow-Leningrad: Izdatelstvo AN SSSR; 1950. (In Russ.)

15. Koshtoyants KhS, Korzhuev PA. [Materials related to the comparative physiology of digestive enzymes. I: Trypsin of cold-blooded and warm-blooded animals, its optimum and heat resistance]. Zoologicheskiy Zhurnal. 1934;13(1):7182. (In Russ.)

16. Kratkiy Tolkovyi Psykholo-Psikhiatricheskiy Slovar. http://dic.academic.ru/searchall.php (In Russ.)

17. Kuz'mina VV. Obschiye Zakonomernosti Membrannogo Pischevareniya u Ryb i Yego Adaptivnaya Perestroyka. [General regularities of membrane digestion in fishes and its adaptive restructuring] (PhD Theses). Moscow: Institut Evoliutsionnoy Morfologii i Ekologii Zhivotnykh; 1986. (In Russ.)

18. Lekakh VA. Kliuch k Ponimaniyu Fiziologii. [The key to Understanding of Physiology: A Tutorial]. Moscow: URSS; 2002. (In Russ.)

19. Liberman SS, Pokrovskaya NV. [Materials related to ecology of sand lizard]. Zoologicheskiy Zhurnal. 1943;22(2):247-56. (In Russ.)
20. Litvinov NA. [On the estimation of body temperature of reptiles as related to external temperature and to size and color adaptability]. Printsipy Ekologii. 2015;4(1):4-16. (In Russ.)

21. Menitskiy DM. [Principles of autoregulation of functional systems]. In: Sudakov KV (ed.). Sistemnyi Analiz Mekhanizmov Povedeniya. [Systems Analysis of Behavioral Mechanisms]. Moscow: Nauka; 1979. (In Russ.)

22. Morev YuB, Smailova TS. [The digestibility of nutrients by worms Tubifex tubifex (Müller, 1773) (Oligochaeta)]. Gidrobiologicheskiy Zhurnal. 1987;23(2):67-71. (In Russ.)

23. Naumov NP. Ekologiya Zhivotnykh [Animal Ecology]. Moscow: Vysshaya Shkola; 1963. (In Russ.)

24. Ryumin AV. [Temperature sensitivity of vertebrate animals and biological way of origin of warm-blooded animals]. Sbornik Studencheskikh Nauchnykh Rabot MGU. 1939(6):55-84. (In Russ.)

25. Ryumin AV. [The significance of temperature in ontogenesis and phylogenesis of animals]. Uspekhi Sovremennoy Biologii. 1940;12(3):50415. (In Russ.)

26. Slonim AD. Zhivotnaya Teplota i Yeyo Reguliatsiya v Organizme Mlekopitayuschikh [Animal Warmth and its Regulation in Mammal Body]. Leningrad: Nayka; 1952. (In Russ.)

27. Slonim AD. Ekologichskaya Fiziologiya Zhivotnykh. [Ecological Physiology of Animals]. Mocow: Vysshaya Shkola; 1971. (In Russ.)

28. Slonim AD. [The doctrine of physiological adaptations]. In: Ekologichaskaya Fiziologiya Zhivotnykh Tom 1. Obschaya Ekologicheskaya Fiziologiya i Fiziologiya Adaptatsiy. [Ecological Physiology of Animals. Vol. 1. General Ecological Physiology and Physiology of Adaptations]. Leningrad: Nauka; 1979. p. 79-182. (In Russ.)

29. Slonim AD. [Habitat temperature and the evolution of temperature homeostasis]. In: Fiziologiya Termoreguliatsii. Leningrad: Nauka; 1984. p. 378-440. (In Russ.)

30. Slonim AD. Fiziologiya Termoreguliatsii. [Physiology of Thermoregulation]. Leningrad: Nauka; 1984. (In Russ.)

31. Slonim AD. Evoliutsiya Termoreguliatsii. [Evolution of Thermoregulation]. Leningrad: Nauka; 1986. (In Russ.)

32. Ushakov BP. [Cytophysiological analysis of adaptations of reptiles to high desert temperatures]. In: Voprosy Tsytologii i Obschey Fiziologii. Moscow-Leningrad; 1960. p. 355-67. (In Russ.)

33. Tsellarius EYu, Tsellarius AYu. [Temperature conditions of activity in desert monitor ( $\mathrm{Va}$ ranus griseus, Reptilia, Sauria)]. Zoologicheskiy Zhurnal. 1997;76(2):206-11. (In Russ.)

34. Tsellarius AYu, Cherlin VA, Men'shikov YuG. [Preliminary report about studies on biology of Varanus griseus (Reptilia, Varanidae) in Middle Asia]. In: Gerpetologicheskiye Issledovaniya. Leningrad: LISS; 1991;(1):61-103. (In Russ.)

35. Cherlin VA. [Humidity conditions in the habitats of saw-scaled viper (Echis multisquamatus) in southern Turkmenia]. In: Voprosy Gerpetologii. Avtoreferaty Dokladov V Vsesoyuznoy Gerpe- 
tologicheskoy Konferentsii. Leningrad: Nauka; 1981. p. 149-50. (In Russ.)

36. Cherlin VA. [Modes of adaptation of reptiles to environmental temperature conditions]. Zhurnal Obshchey Biologii. 1983;44(6):753-64. (In Russ.)

37. Cherlin VA. [Dependence of scalation on climatic factors in the snake genus Echis]. Zoologicheskiy Zhurnal. 1983;62(2);252-8. (In Russ.)

38. Cherlin VA. [On the thermal biology of gray thin-toed gecko (Cyrtopodion russowi), sand racerunner (Eremias scripta) and steppe agama (Trapelus sanguinolentus) in Eastern Karakum desert]. Izvestiya Akademii Nauk Turkmenskoy SSR Seriya Biologicheskikh Nauk. 1988;(5):3643. (In Russ.)

39. Cherlin VA. [The intensity of liver mitochondrial oxidation in different classes of vertebrates under diverse temperatures]. In: Tezisy Nauchnyh Soobscheniy IV Z'yezda Fiziologov Uzbekistana. Tashkent; 1988. p. 140-1. (In Russ.)

40. Cherlin VA. [The populational aspects of thermal adaptations in reptiles]. In: Problemy Populyatsionnoy Ekologii Zemnovodnyh i Presmykayuschikhsya. Moscow: VINITI. 1989;17:135-72. (In Russ.)

41. Cherlin VA. [Stabilization of high temperature in the evolution of vertebrates]. Uspehi Sovremennoy Biologii. 1990;109(3):440-52. (In Russ.)

42. Cherlin VA. [Methods of researches of the thermal biology of reptiles]. In: Ekologiya Zhivotnykh Uzbekistana [Ecology of Animals of Uzbekistan]. Tashkent; 1991. (In Russ.)

43. Cherlin VA. Termobiologiya Reptiliy. Obschiye Svedeniya i Metody Issledovaniya ( $\mathrm{Ru}-$ kovodstvo). [Thermal Biology of Reptiles. General Information and Research Methods (Manual)]. Saint Petersburg: Russko-Baltiyskiy Informatsyonnyi Tsentr "BLITZ"; 2010. (In Russ.)

44. Cherlin VA. Biologicheskiye Osnovy Soderzhaniya Presmykayuschikhsia v Nevole: Tepovoy Faktor. [Biological Basis of Keeping the Reptiles in Captivity: The Thermal Factor]. Saint Petersburg: Russko-Baltiyskiy Informatsyonnyi Tsentr "BLITZ"; 2011. (In Russ.)

45. Cherlin VA. Organizatsiya Protsessa Zhizni kak sistemy. [The Organization of Life Process as a System]. Saint Petersburg: Russko-Baltiyskiy Informatsyonnyi Tsentr "BLITZ"; 2012. (In Russ.)

46. Cherlin VA. Termobiologiya Reptiliy. Obschaya Konsseptsiya. [Thermal Biology of Reptiles. The General Concept]. Saint Petersburg: Russko-Baltiyskiy Informatsyonnyi Tsentr "BLITZ"; 2012. (In Russ.)

47. Cherlin VA. [Difficulties and possible mistakes in field research of thermal biology of reptiles]. In: Sovremennaya Gerpetologiya: Problemy i Puti Ikh Resheniya. Stat'i po Materialam Pervoy Mezhdunarodnoy Konferentsii Molodyh Gerpetologov Rossii i Sopredel'nykh Stran (Sankt-Petersburg, Rossiya, 25-27 Noyabria 2013). Saint Petersburg: ZIN RAN; 2013. p. 32-9. (In Russ.).

48. Cherlin VA. Reptilii: Temperatura I Ekologiya. [Reptiles: Temperature and Ecology]. Saarbrücken, Lambert Academic Publishing; 2014a. (In Russ.)
49. Cherlin VA. [About the article by S.S. Liberman and N.V. Pokrovskaja about the thermal biology of Lacerta agilis (1943)]. Printsipy Ekologii. 2014;3(3):25-32. (In Russ.)

50. Cherlin VA. [Heat adaptations in reptiles and the mechanism of their formation]. Printsipy Ekologii. 2015;4(1):17-76. (In Russ.)

51. Cherlin VA, Muzytchenko IV. [Thermal biology and ecology of reticulate racerunner Eremias grammica, secret toadhead agama Phrynocephalus mystaceus and Lichtenstein's toadhead agama Ph. interscapularis in East Karakum in summer]. Zoologicheskiy Zhurnal. 1983;62(6):897-908. (In Russ.)

52. Cherlin VA, Muzytchenko IV. [On the methods for determining the critical maximum of body temperature of some Middle Asia lizards]. Izvestiya Akademii Nauk Turkmenskoy SSR Seriya Biologicheskikh Nauk. 1984;(5):73-6. (In Russ.)

53. Cherlin VA, Muzytchenko IV. [Seasonal variability of thermobiological characteristics in some arid lizards]. Zoologicheskiy Zhurnal. 1988;67(3):406-16. (In Russ.)

54. Cherlin VA, Tsellarius AYu. [The dependence of behavior of the saw-scaled viper, Echis multisquamatus Cherlin 1981, on temperature in south Turkmenistan]. In: Fauna i Ekologiya Amfibiy i Reptiliy Palearkticheskoy Azii. Leningrad: Nauka; 1981. p. 96-108. (In Russ.)

55. Cherlin VA, Tsellarius AJ, Gromov AV. [On the thermal biology of Teratoscincus scincus in Karakum desert]. Ekologiya. 1983;(2):84-87. (In Russ.)

56. Schmidt-Nielsen K. Zhivotnye Pustyn. [Desert animals]. Leningrad: Nauka; 1972. (In Russ.)

57. Schmidt-Nielsen K. Fiziologiya Zhivotnykh. [Animal physiology]. Moscow: Mir; 1982. (In Russ.)

58. Eckert R, Randall D, Warren B, Kathleen F. Fiziologiya Zhivotnykh: Mekhanizmy Adaptatsii. [Animal physiology: Mechanisms of Adaptation]. Moscow: Mir; 1991. (In Russ.)

59. Entsyklopedicheskiy Slovar po Psykhologii i Pedagogike. http://psychology_pedagogy.academic.ru (In Russ.)

60. Akhmerov RN. Qualitative difference in mitochondria of endothermic and ectothermic animals. FEBS Lett. 1986;198(2):251-5.

61. Alcala AC, Brown WC. Thermal relation of two tropical lizards on Negros Island, Philippine islands. Copeia. 1966;(3):593-4.

62. Amo L, Lopez P, Martin J. Thermal dependence of chemical assessment of predation risk affects the ability of wall lizards, Podarcis muralis, to avoid unsafe refuges. Physiol Behav. 2004;82:913-8.

63. Anderson RA, Karasov WH. Contrasts in energy intake and expenditure in sit-and-wait and widely foraging lizards. Oecologia. 1981;(49):6772.

64. Angilletta MJ. Thermal Adaptation: A Theoretical and Empirical Synthesis. Oxford: Oxford University Press; 2009.

65. Angilletta MJ, Niewiarowski PH, Navas CA. The evolution of thermal physiology in ectotherms. J Thermal Biol. 2002;27:249-68. 
66. Bacci M, Lanza B, Linari L, Tosini G. In vivo skin reflectance of the wall lizard, Podarcis muralis. Applied Spectroscopy. 1992;46(3):510-12.

67. Bakken GS. Measurement and application of operative and standard operative temperatures in ecology. Am Zool. 1992;32:194-216.

68. Baskerville GL, Emin P. Rapid estimation of heat accumulation from maximum and minimum temperatures. Ecology. 1969;(50):514-17.

69. Begon M, Harper JL, Townsend CR. Ecology: Individuals, Populations, and Communities. Oxford; Blackwell; 1986.

70. Bell CJ. The scaling of the thermal inertia of lizards. J Exp Biol. 1980;86:79-85.

71. Bennett AF, Dawson WR. Metabolism. In: Gans C, Dawson WR, eds. Biology of the Reptilia. London-New York: Academic Press. p. 127-223.

72. Bennett AF, Hicks JW, Cullum AJ. An experimental test of the thermoregulatory hypothesis for the evolution of endothermy. Evolution. 2000;54:1768-73.

73. Bennett AF, John-Alder H. Thermal relations of some Australian skinks (Sauna, Scincidae). Copeia. 1986;(1):57-64.

74. Berk ML, Heath JE. An analysis of behavioral thermoregulation in the lizard, Dipsosaurus dorsalis. J Therm Biol. 1975;(1):15-22.

75. Bons J, Dakka A. Capture au Maroc de la vipere des Pyramides, Echis carinatus (Schneider, 1801). C R Soc Sci Nat. Maroc. 1963;(2):55-7.

76. Bowker RG. The infrared reflectivity of the desert lizards Cnemidophorus velox and Sceloporus undulatus. J Therm Biol. 1985;10(3):183-5.

77. Bowker RG, Spindler HS, Tilden A, Bairos VA, Murray R. Reflections on lizard skin: the ultrastructure of the scales of Cnemidophorus exsanguis and Podarcis bacagae. In: Proc. $4^{\text {th }} \mathrm{Or}-$ dinary Gen. Meet. Soc. Eur. Herpetol, Nijmegen, 17-21 Aug. 1987. Nijmegen. 1987; p. 83-6.

78. Brattstrom BH. Body temperatures of reptiles. Amer Midl Naturalist. 1965;73(2):376-492.

79. Cherlin VA. Method of ecology-physiological matrix of species in researches on reptile biology. Gerpetologicheskiye Issledovanoya. Leningrad: LISS; 1991. p.138-46.

80. Cherlin VA. Some Important Aspects of Thermal Biology of Reptiles. Saarbrücken: Lambert Academic Publishing; 2015.

81. Cole LC. Experiments on toleration of high temperatures in lizards with reference to adaptive coloration. Ecology. 1943;24:94-108.

82. Constable JD. Reptiles from the Indian Peninsula in the Museum of Comparative Zoology. Bull Museum Compar Zool Harvard. 1949;2:159-60.

83. Cowles RB, Bogert CM. Preliminary study of the thermal requirements of desert reptiles. Bull Amer Museum Nat Hist. 1944;83:261-96.

84. Dawson WR. On the physiological significance of the preferred body temperatures of reptiles. In: Gates DM, Schmerl RB, eds. Perspectives of Biophysical Ecology. Ecological studies. New York: Springer-Verlag; 1975. p. 443-73.

85. Deranijagala PEP. Some new races of the snakes Erix, Gallophis and Echis. Spolia Zeylanica. 1951;26:147-50.
86. De Witt CB. Effects of body size and wind speed on rates of cooling of lizards. Amer Zool. 1962;2(4):517-8.

87. De Witt CB. Precision of thermoregulation and its relations to environmental factors in the desert iguana Dipsosaurus dorsalis. Physiol Zool. 1967;40(1):49-66.

88. Dodd CK. Infrared reflectance in chameleons (Chameleonidae) from Kenya. Biotropica. 1981;13(3):161-4.

89. Fox W. Effect of temperature on development of scutellation in gater snake, Thamnophis elegans atratus. Copeia. 1948;(4):252-62.

90. Fraser S, Grigg G. Control of thermal conductance is insignificant to thermoregulation in small reptiles. Physiol Zool. 1984;57(4):392400.

91. Glossary of terms for thermal physiology. Third Edition revised by The Commission for Thermal Physiology of the International Union of Physiological Sciences (IUPS Thermal Commission). J Thermal Biol. 2003;(28):75-106.

92. Greenwald OE. Thermal dependence of striking and prey capture by gopher snakes. Copeia. 1974;1:141-8.

93. Greenwald OE, Kanter ME. The effects of temperature and behavioral thermoregulation on digestive efficiency and rate in corn snakes (Elaphe guttata guttata). Physiol Zool. 1979;52(3):398-408.

94. Hammerson GA. Head-body temperature differences monitored by telemetry in the snake Masticophis flagellum piceus. Compar Biochem Physiol. 1977;57(4A):399-402.

95. Heath JE. Behavioral regulation of body temperature in poikilotherms. The Physiologist. 1970;13:339-410.

96. Hertz PE. Thermal passivity of a tropical forest lizard, Anolis polylepis. J. Herpetol. 1974;8:323-7.

97. Hertz PE, Huey R, Nevo E. Homage to Santa Anita: thermal sensitivity of sprint speed in agamid lizards. Evolution. 1983;37:1075-84.

98. Horton DR. Lizard scales and adaptation. Syst Zool. 1972;21(4):441-3.

99. Huey RB. Behavioral thermoregulation in lizards: importance of associated costs. Science. N.Y. 1974;(184):1001-3.

100. Huey R. Temperature, physiology, and the ecology of reptiles. In: Gans C, Poug, eds. Biology of the Reptilia. Physiology. London: Academic Press; 1982. p. 25-91.

101. Huey R, Peterson CR, Arnold SJ, Porter WP. Hot rocks and not-so-hot rocks: retreatsite selection by garter snakes and its thermal consequences. Ecology. 1989;(70):931-44.

102. Huey RB, Slatkin M. Cost and benefits of lizard thermoregulation. Quart Rev Biol. 1976;(51):363-84.

103. Huey RB, Webster TP. Thermal biology of a solitary lizard: Anolis marmoratus of Guadeloupe, Lesser Antilles. Ecology. 1975;(56):445-52.

104. Johnson CR. Head-body temperature differences in Varanus gouldii (Sauria: Varanidae). Comp Biochem Physiol. 1972;43A(4):1025-29.

105. Klauber LM. Four papers on the application of the statistical methods to herpetological prob- 
lems. III. The correlation between scalation and life zones in San Diego County snakes. Bull Zool Soc San Diego. 1941;(17):73-9.

106. Licht P. The effect of temperature on hart rates of lizards during rest and activity. Physiol Zool. 1964;(38):129-37.

107. Licht $P$. Thermal adaptation in the enzymes of lizards in relation to preferred body temperatures. Amer Assoc Adv Sci Publ. 1967;84:131-45.

108. Magnuson JJ, Beitinger TL. Stability of temperatures preferred by centrarchid fishes and terrestrial reptiles. In: Reese ES, Lighter F, eds. Contrasts in Behavior. New York: Wiley Interscience; 1978. p. 181-216.

109. Matsuzawa Y, Sato K, Sakamoto W, Bjorndal KA. Seasonal fluctuations in sand temperature: effects on the incubation period and mortality of loggerhead sea turtle (Caretta caretta) pre-emergent hatchlings in Minabe, Japan. Marine Biol. 2004; 140:639-46.

110. McGinnis SM. Preferred body temperature of the western fence lizard. Science. 1966;152:1090-1.

111. Mitchell D, Snellen JW, Atkins AR. Thermoregulation during fever: change of set-point or change of gain. Pflügers Archiv. 1970;(321):293-302.

112. Murrish DE, Schmidt-Nielson K. Exhaled air temperature and water conservation in lizards. Resp Physiol. 1970;10:151-8.

113. Nelson DO, Heath JE, Prosser CL. Evolution of temperature regulatory mechanisms. Amer Zool. 1984;(24):791-807.

114. Nilson G. Ovarian cycle and reproductive dynamics in the female Adder, Vipera berus (Reptilia, Viperidae). Amphibia-Reptilia. 1981;(2):63-82.

115. Norris KS. The ecology of the desert iguana, Dipsosaurus dorsalis. Ecology. 1953;34(2):265-87.

116. Norris KS. Color adaptations in desert reptiles and its thermal relationships. In: Milstead WW, ed. Lizard Ecology: A Symposium. 1967. p. 162-229.

117. Parker JR. Some effects of temperature and moisture upon Melanoplus mexicanus mexicanus Saussure and Camnula pellucida Scudder (Orthoptera). Univ Montana Agri Exp Sta Bull. 1930;(223):1-132.

118. Parker HW. The Snakes of Somaliland and the Sokotra Islands. Leiden; 1949.

119. Parker SL, Andrews RM. Incubation temperatures and phenotypic traits in Sceloporus undulatus: implications for the northern limits of distribution. Oecologia. 2006;151(2):218-31.

120. Porter WP, Mitchell JW, Beckman WA, DeWitt CB. Behavioral implications of mechanistic ecology. Oecologia. 1973;(13):1-54.

121. Porter WP, Norris KS. Lizard reflectivity change and its effect on light transmission through body wall. Science. 1969;163:52-4.
122. Pough FH, McFarland W. A physical basis for head-body temperature differences in reptiles. Comp Biochem Physiol. 1976;53A:301-3.

123. Rand AS, Humphrey SS. Interspecific competition in the tropical rain forest: ecological distribution among lizards at Belem, Para. Proc US Natl Mus. 1968;(125):1-17.

124. Rice GE, Bradshaw SD. Changes in dermal reflectance and vascularity and their effects on thermoregulation in Amphibolurus nuchalis (Reptilia: Agamidae). J Comp Physiol. 1980;B135(2):139-46.

125. Ruibal R. Thermal relations of five species of tropical lizards. Evolution. 1961;(15):98-111.

126. Ruibal R, Philibosian R. Eurythermy and niche expansion in lizards. Copeia. 1970;(4):64553.

127. Seymour RS, Bennett-Stamper CL, Johnston SD, Carrier DR, Grigg GC. Evidence for endothermic ancestors of crocodiles at the stem of archosaur evolution. Physiol Biochem Zool. 2004;77:1051-67.

128. Soule M, Kerfoot WC. On the climatic determination of scale size in a lizard. Syst Zool. 1972;(21):97-100.

129. Spellerberg LF. Thermal ecology of allopatric lizards (Sphenomorphus) in Southeast Australia. Physiological aspects of thermoregulation. Oecologia. 1972(9):385-98.

130. Stebbins RC, Lowenstain JM, Cohen NW. A field study of the Lava Lizard (Tropidum albemarlensis) in the Galapagos Islands. Ecology. 1967;(48):839-51.

131. Talbot HE, Livezey R. Integumental reflectivity of live Sceloporus occidentalis occidentalis from four habitats. Herpetologica. 1964;19(4):269-74.

132. Tercafs RR. Transmission of ultraviolet, visible, and infrared radiation through the keratinous layer of reptile skin. Ecology. 1963;(44):214-18.

133. Valenzuela N, Botero R, Martinez E. Field study of sex determination in Podocnemis expan$s a$ from Colombian Amazonia. Herpetologica. 1997;53(3):390-8.

134. Van Berkum FH. The significance of preferred body temperatures of lizards. Amer Zool. 1980;(2):734.

135. Webb G, Johnson CR. Head-body temperature differences in turtles. Comp Biochem Physiol. 1972;43A:593-611.

136. Webb G, Johnson CR, Firth BT. Head-body temperature differences in lizards. Physiol Zool. 1972;45(2):130-42.

137. Whillans TH, Crossman EJ. Morphological parameters and spring activities in a central Ontario population of midland painted turtle, Chrysemys picta marginata (Agassiz). Can Field Naturalist. 1977:91(1):47-57. 